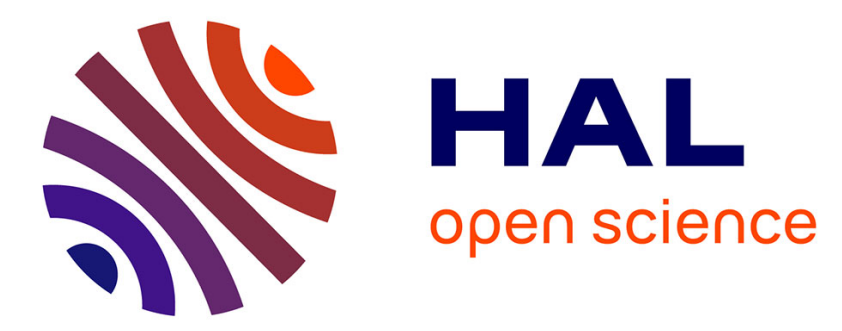

\title{
Graphene-Based Materials In Vitro Toxicity and Their Structure-Activity Relationships: A Systematic Literature Review
}

\author{
Salma Achawi, Jérémie Pourchez, Bruno Feneon, Valérie Forest
}

\section{To cite this version:}

Salma Achawi, Jérémie Pourchez, Bruno Feneon, Valérie Forest. Graphene-Based Materials In Vitro Toxicity and Their Structure-Activity Relationships: A Systematic Literature Review. Chemical Research in Toxicology, 2021, 10.1021/acs.chemrestox.1c00243 . hal-03330815

\section{HAL Id: hal-03330815 https://hal.science/hal-03330815}

Submitted on 1 Sep 2021

HAL is a multi-disciplinary open access archive for the deposit and dissemination of scientific research documents, whether they are published or not. The documents may come from teaching and research institutions in France or abroad, or from public or private research centers.
L'archive ouverte pluridisciplinaire HAL, est destinée au dépôt et à la diffusion de documents scientifiques de niveau recherche, publiés ou non, émanant des établissements d'enseignement et de recherche français ou étrangers, des laboratoires publics ou privés. 


\section{Graphene-based materials in vitro toxicity and their structure-activity relationships - A systematic literature review.}

Salma Achawi ${ }^{\dagger} \S$, Jérémie Pourchez ${ }^{\S}$, Bruno Feneon ${ }^{\dagger}$ and Valérie Forest ${ }^{\S *}$

${ }^{\dagger}$ Manufacture Française des Pneumatiques Michelin, Place des Carmes Déchaux, 63040 Clermont-Ferrand Cedex 9, France

$\S$ Mines Saint-Etienne, Univ Lyon, Univ Jean Monnet, INSERM, U1059 Sainbiose, Centre CIS, F-42023 Saint-Etienne, France.

* Corresponding author: Valérie Forest:

Mines Saint-Etienne, 158 cours Fauriel, CS 62362, 42023 Saint-Etienne Cedex 2. France.

Email: vforest@emse.fr 


\section{Table of Contents Graphic}

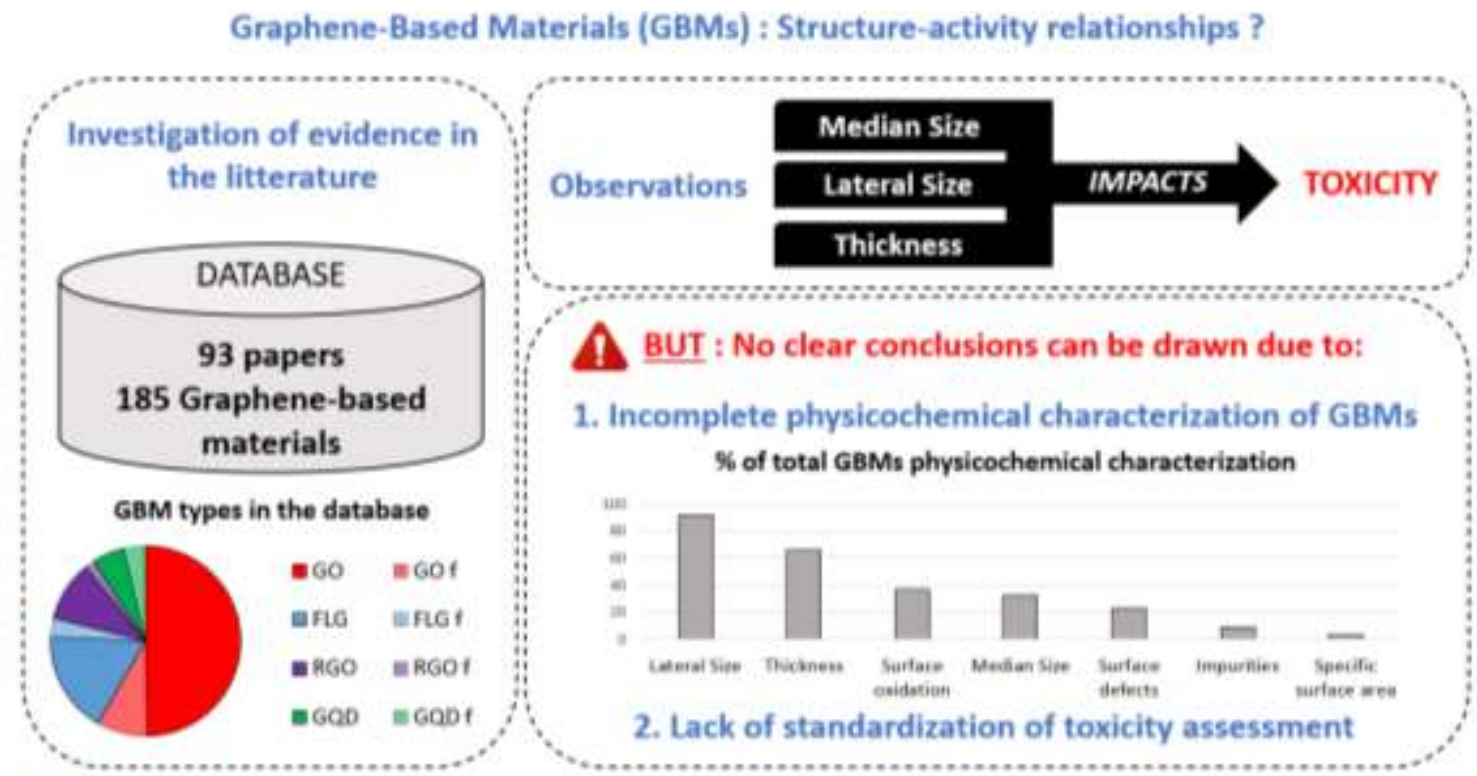

$\rightarrow$ Optimized toxicity assessment and physicochemical characterization proposed in this paper. 


\begin{abstract}
The unique properties of graphene-based materials (GBMs) placed them among the most exciting nanomaterials of the past decade. Scientists and industrials are looking forward to working with not only performant, but also safe, sustainable GBMs. Designing a safer-by-design GBM implies to acquire the knowledge of which physicochemical characteristics (PCCs) can increase toxicity. In this systematic review, we extracted data from the literature to provide the available information about the structure-activity relationship of GBMs. 93 papers studying a total of 185 GBMs were included. Graphene oxides (GOs) and Few-layer graphenes (FLGs) are the most studied GBMs. While reduced graphene oxides (rGOs) were often classified as poorly oxidant and weakly cytotoxic, graphene quantum dots (GQDs) were mostly moderately or highly cytotoxic. FLGs demonstrated relationships between median size and oxidative stress, between lateral size and both cytotoxicity and oxidative stress and between thickness and cytotoxicity. We also underlined relationships between median size, lateral size and thickness of GOs and oxidative stress. However, it appeared difficult to highlight clear structure-activity relationships for most PCCs and biological endpoints because despite a large amount of available data, the GBMs are often too poorly characterized in terms of PCCs descriptors and the biological endpoints investigation is not standardized enough. There is an urgent need for a better standardization of the experimental investigation of both PCCs and biological endpoints to allow research teams to play a part in the collaborative work toward the construction of a safer-by-design GBM through a better understanding of their key toxicity drivers.
\end{abstract}

Keywords: Graphene-based Materials, Structure-activity-relationship, Physicochemical characterization, Toxicity, Safer-by-design. 


\section{Introduction}

Graphene is an allotrope of carbon and its properties at single atom level were uncovered in 2004. It is composed of a single layer of atoms arranged in a two-dimensional honeycomb pattern(1). However, the term graphene is often generically used to define various types of graphene-based materials. Indeed, different families of graphene-based materials (GBMs)(2) are usually described:

- Few-layer graphene (FLG), obtained by either a mechanical or a chemical exfoliation of graphite(3).

- Graphene Oxide (GO), obtained by an oxidation of graphite, mostly by using Hummers method involving the use of various oxidizing reagents and acids(4).

- Reduced Graphene Oxide (rGO), obtained after the reduction of graphene oxide through chemical, thermal or other types of reduction(5).

- Graphene Quantum Dot (GQD) is a piece of graphene, small enough to cause exciton confinement. Its diameter measures typically less than $20 \mathrm{~nm}(6)$.

All these families of GBM can be functionalized (FLGf, GOf, rGOf, GQDf). Even if they all fall within the family of Graphene Based Materials (GBMs), their synthesis process as well as their physicochemical characteristics (PCCs) can strongly vary. Hence, it is crucial to consider individually these subfamilies of GBMs.

Since the discovery of graphene, GBMs have emerged and raised growing interest. Their various properties such as mechanical strength(7) and conductivity(8), still recently investigated(9), make these materials extremely promising and versatile. These properties encouraged the development of various GBM-based innovations such as water treatment(10). Besides, the field of medicine has high expectations for these materials $(11,12)$. The GBM market has consequently been increasing in recent years and will most likely develop over the next decade(13). 
However, the successful integration of GBMs on the market depends on their safety, which need to be rigorously investigated(14). Determining and addressing the potential risks caused by GBMs is a critical responsibility for industries willing to integrate them into their processes(15). Risk management through control banding is a widespread method, already widely used for chemicals and recently emerged as a contribution for nanomaterials risk management(16). Control Banding is a tool that combines risk assessment and management and is proposed for ensuring the safety of workers exposed to a new product for which only little information are available. Briefly, "hazard bands" of this new product are allocated according to the hazard level of known products similar to those used. Each band corresponds to a risk control strategy(17). For example, a GBM can be classified in a hazard band depending on the known toxicity (e.g. determined in vitro or in vivo on mammalian models) of a similar GBM coming from a same subfamily. Besides, an exposure band will be also defined, depending on the ease of exposure or the quantity used. Crossing these bands will lead to a certain level of risk management required at the workstation, involving protections or restrictions.

Allocating a hazard band to nanomaterials (such as GBMs) can be challenging since their toxicity databases are relatively poor. Besides, the number of nanomaterials for industrial applications is increasing extremely fast(18). This situation made a case-by-case approach for toxicity assessment costly and time consuming. Therefore, alternative and complementary toxicity assessments such as grouping, read across and Q(SAR) were developed and proposed this last decade(19). It enabled scientific community to make considerable progress in the knowledge of nanotoxicology and specifically the understanding of certain mechanisms of action(20). Meanwhile, the safer-bydesign approach associated with a control banding strategy is increasingly considered as a leading paradigm in nanotoxicity and integrates the anticipated safety impacts of materials into the design 
and production phases $(21,22)$. Therefore, this approach implies that safety should be an early concern for nanomaterials development, and that the adverse effects of these materials should be known or investigated from the early phases of the creation process: accomplishing a safer-bydesign nanomaterial requires a comprehensive study of its adverse effects and the knowledge of which PCCs will affect its toxicity. Indeed, PCCs have been shown to strongly affect nanomaterials toxicity. For example, the GBM oxidation was reported to be a critical factor for its toxicity. However, this finding is disputed in the literature: an increasing oxidation appears to increase toxicity(23), whereas for some studies, no direct impact of oxidation was observed(24). In order to have a clearer overview of the potential impacts of PCCs on GBMs' toxicity, we gathered few studies that observe the toxicity impact of various GBMs differing by their lateral size(25)(26)(27)(28)(29)(30)(31), $\quad$ oxidation(24)(32)(33)(52)(53) and functionalization(34)(35)(36)(37)(38)(39) (Table 1, 2 and 3). For lateral size, most studies claim that the smaller GBMs show a higher toxicity. For surface oxidation (expressed in atomic percentage, mostly measured with XPS) the most oxidized GBMs show a higher toxicity. Moreover, the functionalization seems to lower the toxicity. These observations can be discussed: firstly, the nature of functional groups is so variable that it is difficult to have strong statement when it comes to functionalization impact on toxicity. Secondly, discussing the impact of lateral size of GBMs measuring a maximum of $10 \mu \mathrm{m}$ is a limit knowing that some biological effects (including frustrated phagocytosis) can only be observed from a threshold of $20 \mu \mathrm{m}$ (40). 
Table 1 - Papers studying GBMs that vary by their lateral size.

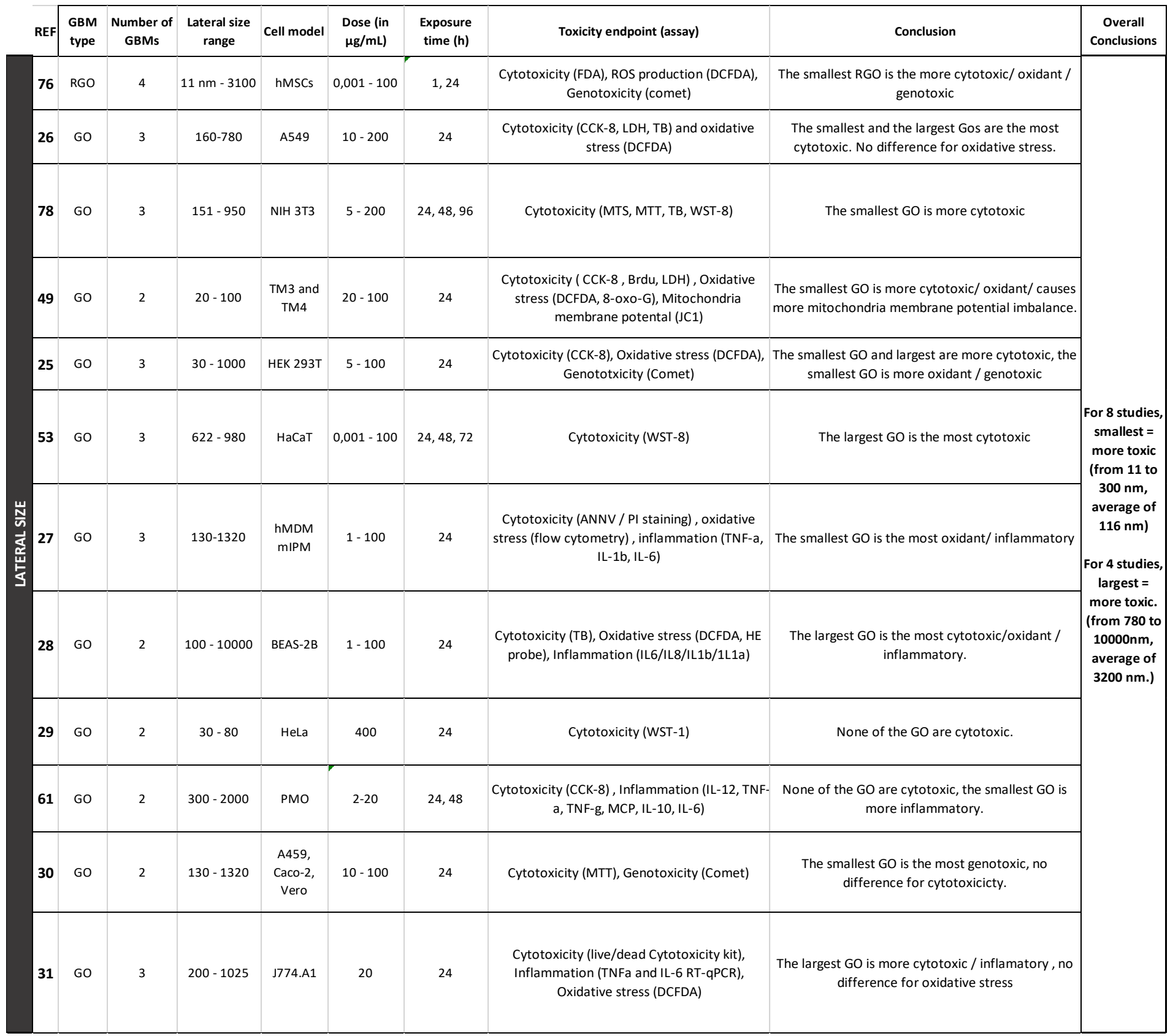


Table 2 - Papers studying GBMs that vary by their oxidation state.

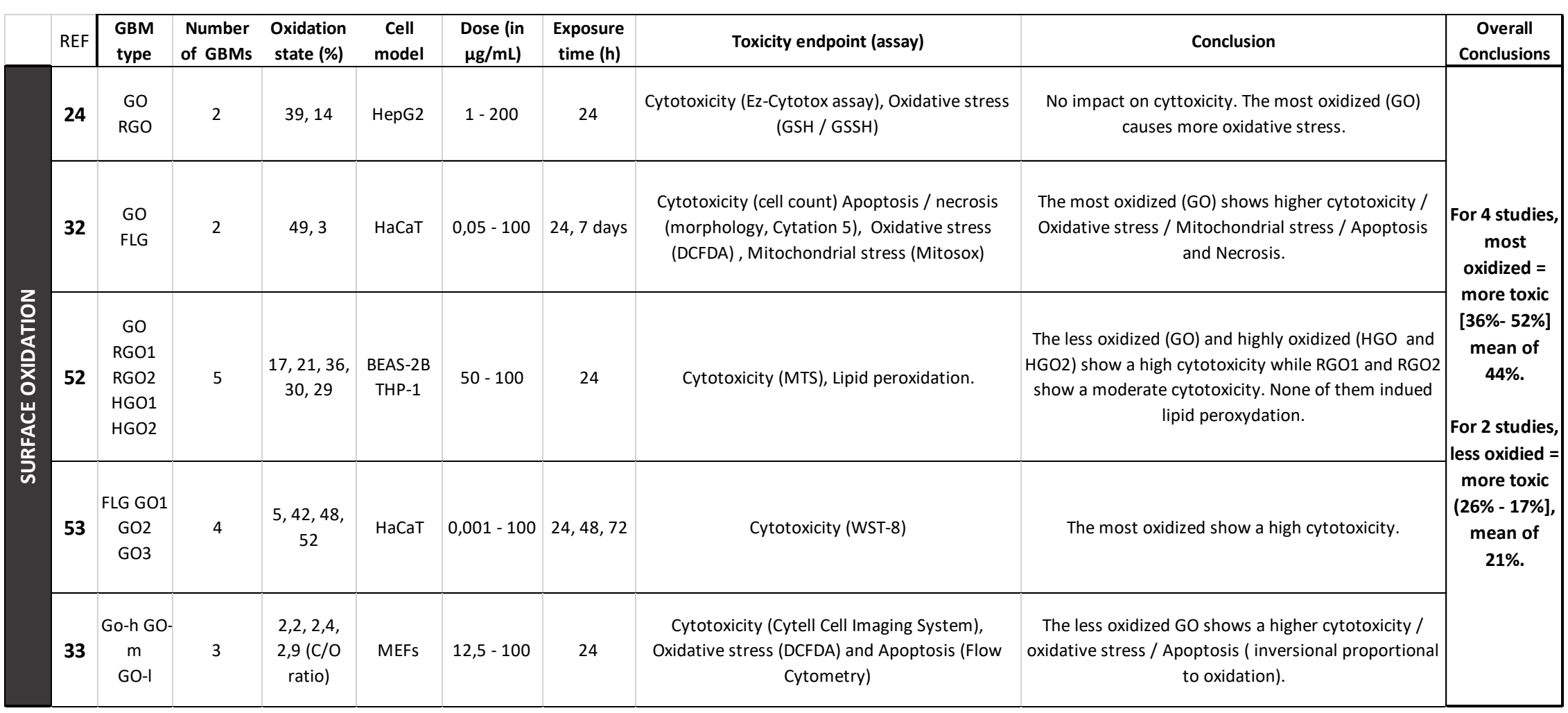


Table 3 - Papers studying GBMs that vary by their functionalization.

\begin{tabular}{|c|c|c|c|c|c|c|c|c|c|}
\hline REF & $\begin{array}{l}\text { GBM } \\
\text { type }\end{array}$ & $\begin{array}{l}\text { Number } \\
\text { of GBMs }\end{array}$ & $\begin{array}{l}\text { Functionaliza } \\
\text { tion (fctz) }\end{array}$ & $\begin{array}{c}\text { Cell } \\
\text { model }\end{array}$ & $\begin{array}{l}\text { Dose (in } \\
\mu \mathrm{g} / \mathrm{mL} \text { ) }\end{array}$ & $\begin{array}{l}\text { Exposure } \\
\text { time (h) }\end{array}$ & Toxicity endpoint (assay) & Conclusion & $\begin{array}{c}\text { Overall } \\
\text { Conclusions }\end{array}$ \\
\hline 34 & GNP & 3 & $\begin{array}{l}\text { none, } \mathrm{COOH}, \\
\quad \mathrm{NH} 2\end{array}$ & & $5-150$ & 24 & Cytotoxicity (Ez cytotox) & $\begin{array}{l}\text { The unfunctionalized GNP shows a greater } \\
\text { cytotoxicity than then COOH-GNP and NH2-GNP. }\end{array}$ & \multirow{6}{*}{$\begin{array}{l}\text { Overall, fctz } \\
\text { appears to } \\
\text { lower } \\
\text { toxicity but it } \\
\text { depends on } \\
\text { the nature of } \\
\text { fctz. }\end{array}$} \\
\hline 35 & GQD & 3 & $\begin{array}{l}\text { none, } \mathrm{COOH}, \\
\quad \mathrm{NH} 2\end{array}$ & HL-7702 & $12,5-200$ & 24 & $\begin{array}{l}\text { Cytotoxicity (LDH), Oxidative stress (DCFDA), } \\
\text { Apoptosis (expression of regulator genes) }\end{array}$ & $\begin{array}{c}\text { No impact on cytotoxicity/oxidation (all non } \\
\text { cytotoxic/oxidant), functionalization affect apoptotic } \\
\text { genes regulation (COOH-GQD causes no imbalance } \\
\text { compared to control and non functionalized GQD } \\
\text { whereas NH2-GQD causes more imbalance than } \\
\text { control and non functionalized GQD) } \\
\end{array}$ & \\
\hline$\frac{Z}{2}$ & GO & 3 & $\begin{array}{l}\text { none, PEG, } \\
\text { BSA }\end{array}$ & $\begin{array}{c}\text { 7702-3d } \\
\text { MRC-5- } \\
\text { 3d, U937- } \\
3 d\end{array}$ & $25-200$ & $\begin{array}{l}24,48 \\
72\end{array}$ & $\begin{array}{c}\text { Cytotoxicity (MTT, CCK-8) and Genotoxicity (DNA } \\
\text { tail) }\end{array}$ & $\begin{array}{l}\text { The PEG-GO shows no cytotoxicity/genotoxicity, BSA- } \\
\text { GO shows a low cytotoxicity.genotoxicity and non-fct } \\
\text { GO shows a strong cytotoxicity/genotoxicity. }\end{array}$ & \\
\hline$\frac{2}{\mathrm{E}}$ & GO & 2 & $\begin{array}{l}\text { 3PEG and } \\
\text { 6PEG } \\
\text { (number of } \\
\text { PEG chains) }\end{array}$ & $\begin{array}{l}\text { Saos-2, } \\
\text { MC3T3- } \\
\text { E1, } \\
\text { RAW264, } \\
7\end{array}$ & 75 & $\begin{array}{l}24,48 \\
72\end{array}$ & $\begin{array}{l}\text { Cytotoxicity (PI), ROS (DCFDA), Inflammation } \\
\text { (TNF-a production) }\end{array}$ & $\begin{array}{c}\text { Both functionalized GO show cytotoxicity, oxidative } \\
\text { stress and 6PEG GO shows a higher inflammation at } \\
24 \mathrm{~h} \text { exposure time. Results differ depending on cell } \\
\text { type. }\end{array}$ & \\
\hline 38 & GO & 5 & $\begin{array}{l}\text { none, } \mathrm{NH} 2 \text {, } \\
\text { PAM, PAA, } \\
\text { PEG }\end{array}$ & NR8383 & $2-100$ & 24 & Cytotoxicity (CCK-8, LDH) & $\begin{array}{l}\mathrm{NH} 2, \text { PAA and PEG fct lowers cytotoxicity, PAM fct } \\
\text { increases cytotoxicity compared to unfct GO. }\end{array}$ & \\
\hline 39 & GQD & 3 & $\begin{array}{l}\mathrm{NH} 2, \mathrm{COOH}, \\
\mathrm{OH}\end{array}$ & A549 & $10-200$ & 24 & $\begin{array}{c}\text { Cytotoxicity (WST-1) Apoptosis (annexin-V- } \\
\text { FITC/PI staining) }\end{array}$ & $\begin{array}{l}\text { OH-GQD is the only one to show } \\
\text { cytotoxicity/apoptosis increase, NH2-GQD and COOH- } \\
\text { GQD show no cytotoxicity/apoptosis increase. }\end{array}$ & \\
\hline
\end{tabular}


Pooling each individual conclusions of the available studies dealing with GBMs toxicity might allow us to highlight which PCCs have the higher impact on its biological effect on a global scale, enabling us to make one more step toward a safer-by-design GBM. In this paper, through a systematic review, we aimed to gather available data in the literature to provide a holistic view of the structure-activity relationship of GBMs.

\section{Material and Method}

Our approach is summarized in Figure 1.

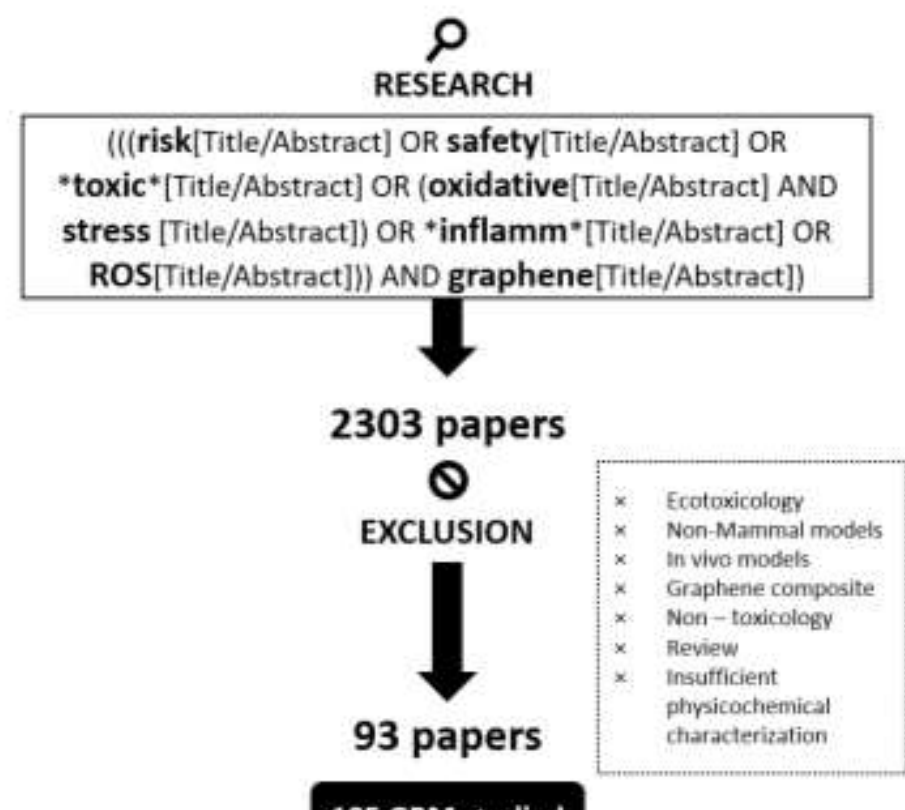

185 GBM studied

Figure 1- Selection process for papers.

\subsection{Search engine}

We chose to use PubMed, as it is one of the major platforms in toxicity assessment and health science publications. We used the following research: 
(((risk[Title/Abstract] OR safety[Title/Abstract] OR *toxic*[Title/Abstract] OR

(oxidative[Title/Abstract] AND stress [Title/Abstract]) OR *inflamm*[Title/Abstract] OR

ROS[Title/Abstract])) AND graphene[Title/Abstract]).

We found 2303 results.

The term *toxic* allowed us to make sure to select major endpoints dealing with toxicity (i.e genotoxicity, cytotoxicity). Moreover, 'risk' is a word often added to the abstract of articles dealing with toxicity or safety. We added 'oxidative stress', 'ROS' and '*inflamm*' because they are well known modes of action for GBM and major endpoints in in vitro toxicity. To be as exhaustive as possible, we did not add any exclusion terms. With our research, any article including at least one of these terms AND the word 'graphene' is added to our database.

\subsection{Exclusion criteria}

We chose to focus on human health. Hence, mammalian models appeared more relevant for this purpose. Moreover, we made the decision to include only in vitro studies. This type of model represents a major part of the literature. Furthermore, in vivo studies can have heterogeneous exposure protocol (administration route, duration of exposure or dose) which makes the analysis of the results challenging, and a gathering of the data sometimes irrelevant. When we had a paper describing both in vivo and in vitro work, we classified in vitro assays in a table for in vitro, and the in vivo assays in a table for in vivo; we only presented in vitro results in this paper. Based on the reading of the abstracts, the text of the article and the supplementary data, we decided to exclude articles dealing with:

- Ecotoxicology.

- Non-mammalian models. 
- In vivo studies.

- Graphene composite.

- Non - toxicology issues or assays.

- No minimum characterization: lateral size was the only minimal characterization. When the lateral size was missing and when the GBM was considered small enough $(<1000 \mathrm{~nm})$, the size distribution measured by DLS was considered as a sufficient characterization for inclusion in the database.

- Too wide lateral size range (for example: $1-10 \mu \mathrm{m}$ ).

- Review articles.

We finally obtained 93 articles, regrouping the study of 185 GBMs. The list of these publications is presented in Figure S4 (supplementary information).

\subsection{Toxicity classification}

We classified the data in a table presented in supplementary information S1. We collected every characterization of the GBMs as well as their measured endpoints, and every information that could be relevant for the final analyses.

Briefly, to conclude on the in vitro toxicity of each GBM, we attributed them a toxicity classification (no/low toxicity, moderate toxicity, and high toxicity) based on the exposure dose that led to a significantly biological response when compared to negative control. The method is described in Figure S1.

\subsection{Investigation of potential structure-activity relationships}


We first determined if we collected enough data to study a potential correlation between a biological endpoint and a PCC. If we had less than $2.5 \%$ of our database characterized for a PCC and a biological endpoint (which represents less than 6 GBMs available), we did not consider having enough information to study a potential correlation between this PCC and this biological endpoint. We then aimed to highlight a potential relationship between each PCCs and biological endpoints. To that end, we performed a data treatment to build 2D point cloud graphs, allowing us a visual insight of a possible correlation. We wanted to consider individually exposure time for toxicity assessment. Hence, we separated short ( $\leq 12$ hours), medium (24h) and long ( $\geq 48$ hours) exposure for each endpoint. In the following section, we chose to present the results that could reflect a potential relationship. The other graphs can be consulted in Figure S2.

\section{Results}

\subsection{Database description}

Overall, 166 GBMs were studied in these 84 papers. GO and FLG are the most studied GBMs (Figure 2A) with respectively $45.97 \%$ and $21.8 \%$ of all GBMs belonging to these subfamilies (representing respectively $57 \%$ and $32.7 \%$ of all selected papers). The toxicity of functionalized GBMs is poorly studied since the 4 subfamilies GOf, FLGf, rGOf and GQDf represent less than $16.5 \%$ of all GBMs and $18.7 \%$ of the selected papers. 


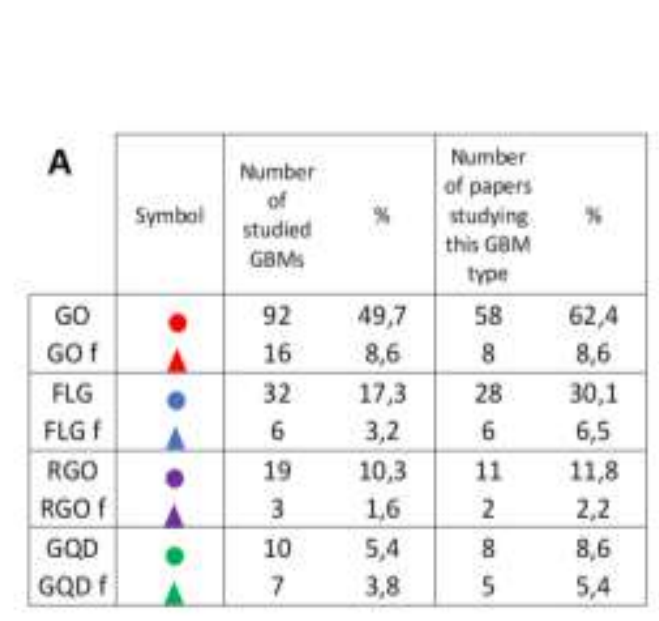

Figure 2 - A) Repartition of GBM types
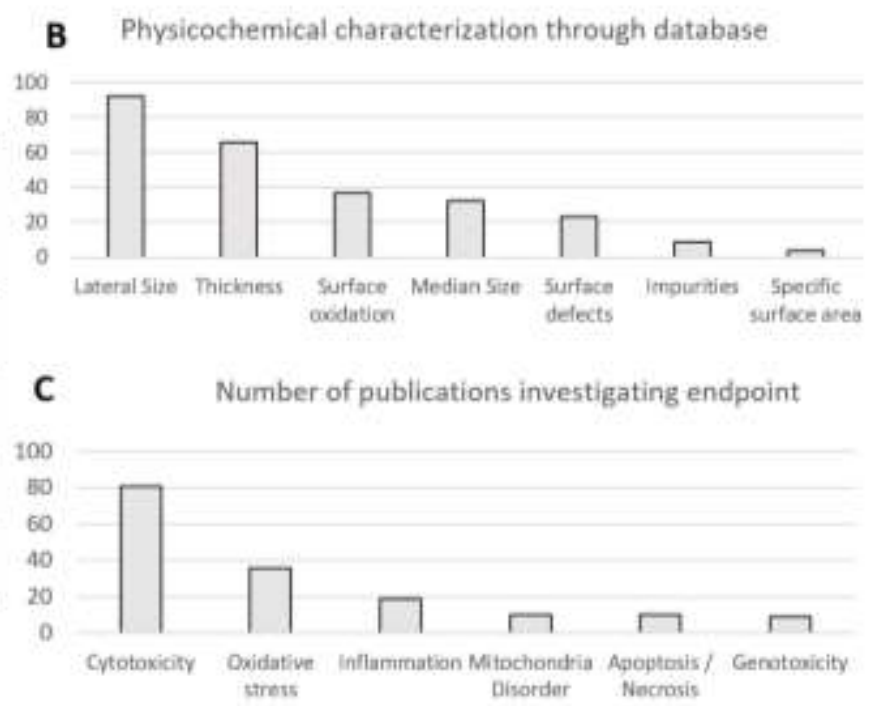

B) GBM physicochemical characterization C) In vitro endpoints.

The physicochemical characterization of these GBMs was rarely exhaustive (Figure 2B). As described in material and methods, the measurement of lateral size was an inclusion criterion hence it is often described in our database ( $91.9 \%$ of the GBMs were characterized for lateral size). When a GBM was small enough $(<1 \mu \mathrm{m})(41)$ and its lateral size was not measured, we considered the measurement of the size distribution (through DLS) as a sufficient characterization to include this GBM in our database. Then thickness, surface oxidation and median size distribution and oxidation were the most measured PCCs with respectively $66 \%, 37 \%$ and $32 \%$ of the total GBMs characterized.

The most investigated biological endpoints (Figure 2C) are clearly cytotoxicity and oxidative stress, which are respectively described in $81 \%$ and $36 \%$ of the papers. The investigation of inflammation (19\% of the publications), genotoxicity $(8.4 \%)$, mitochondrial disorder $(8.4 \%)$ and apoptosis or necrosis $(10 \%)$ is rarest. Highlighting potential structure-activity relationships will obviously be easier if the structure (the PCCs) as well as the activity (the endpoints) of the GBMs 
are measured. Hence, we can expect to analyze the impact of the most described PCCs (which are as described above, lateral size, thickness, size distribution and oxidation) on the most described endpoints (also described above as cytotoxicity and oxidative stress).

In the following section, we will present the physicochemical characteristics that appear to have an impact on toxicity endpoints. We attributed GBMs type colors and shapes, as presented in the table Figure 2A. This would allow highlighting a potential relationship that could be type dependent.

\subsection{Overview of the hazard assessment of the different subfamilies of GBMs}

In Table 4, we introduced toxicity impacts depending on the GBM type. The data presented here is a percentage of the GBMs that show a low, moderate, or high response for major endpoints: cytotoxicity, oxidative stress and genotoxicity. For example, for the early cytotoxicity $(<12 \mathrm{~h})$ of the Few-layer graphene (FLG), 2 FLGs were tested and classified as poorly toxic, 0 as moderately toxic and 1 as highly toxic. Our database included 51 FLGs, with 3 FLGs tested for early cytotoxicity, so we concluded that $66.7 \%$ of our FLGs showed a low early cytotoxicity $\left(\frac{2}{3} \times 100=66.7 \%\right), 0 \%$ a moderate toxicity $\left(\frac{0}{3} \times 100=0 \%\right)$ and $33.3 \%$ a high toxicity $\left(\frac{1}{3} \times 100=33.3 \%\right)$. The number of GBMs tested for each endpoint should obviously be considered when studying the percentages. 
Table 4 - Percentage (number of GBMs of each subfamily in each toxicity class/number of total GBMs of a subfamily) of toxicity assessment depending on GBM subfamilies.

\begin{tabular}{|c|c|c|c|c|c|c|c|c|c|c|c|c|c|c|c|c|c|c|c|c|c|c|c|c|c|c|c|c|c|c|c|c|c|c|c|c|c|c|}
\hline \multirow[b]{3}{*}{ GBM type } & & \multirow[b]{3}{*}{$\begin{array}{c}\text { total of } \\
\text { GBM type } \\
\end{array}$} & \multicolumn{12}{|c|}{ Cytotoxicity } & \multicolumn{12}{|c|}{ Oxidative Stress } & \multicolumn{12}{|c|}{ Genotoxicity } \\
\hline & & & \multicolumn{4}{|c|}{$\leq 12 \mathrm{~h}$} & \multicolumn{4}{|c|}{$24 \mathrm{~h}$} & \multicolumn{4}{|c|}{$\geq 48 \mathrm{~h}$} & \multicolumn{4}{|c|}{$\leq 12 \mathrm{~h}$} & \multicolumn{4}{|c|}{$24 \mathrm{~h}$} & \multicolumn{4}{|c|}{$\geq 48 \mathrm{~h}$} & \multicolumn{4}{|c|}{$\leq 12 \mathrm{~h}$} & \multicolumn{4}{|c|}{$24 \mathrm{~h}$} & \multicolumn{4}{|c|}{$\geq 48 \mathrm{~h}$} \\
\hline & & & \begin{tabular}{|c}
$\begin{array}{c}\text { nof GBM } \\
\text { in each } \\
\text { endpoint }\end{array}$ \\
\end{tabular} & Low & Mod & High & $\begin{array}{c}\text { nof GBM } \\
\text { in each } \\
\text { endpoint }\end{array}$ & Low & Mod & High & \begin{tabular}{|c}
$\begin{array}{c}\text { nof GBM } \\
\text { in each } \\
\text { endpoint }\end{array}$ \\
end
\end{tabular} & Low & Mod & High & \begin{tabular}{|c} 
nof GBM \\
in each \\
endpoint
\end{tabular} & Low & Mod & High & \begin{tabular}{|c} 
nof GBM \\
in each \\
endpoint
\end{tabular} & Low & Mod & High & \begin{tabular}{|c}
$\begin{array}{c}\text { nof GBM } \\
\text { in each } \\
\text { endpoint }\end{array}$ \\
\end{tabular} & Low & Mod & High & \begin{tabular}{|l}
$\begin{array}{c}\text { nof GBM } \\
\text { in each } \\
\text { endpoint }\end{array}$ \\
\end{tabular} & Low & Mod & High & $\begin{array}{c}\text { nof GBM } \\
\text { in inach } \\
\text { endpoint }\end{array}$ & Low & Mod & High & \begin{tabular}{|c}
$\begin{array}{c}\text { nof GGM } \\
\text { in each } \\
\text { endpoint }\end{array}$ \\
\end{tabular} & Low & Mod & High \\
\hline \multirow{2}{*}{ FLG } & $\mathrm{n}$ GBM & 51 & \multirow{2}{*}{3} & 2 & 0 & 1 & \multirow{2}{*}{25} & 7 & 11 & 7 & \multirow{2}{*}{$\varepsilon$} & 2 & 4 & 2 & \multirow{2}{*}{7} & 2 & 1 & 4 & \multirow{2}{*}{1} & 6 & 3 & 1 & & 3 & 1 & 0 & & 0 & 0 & 0 & & 3 & 1 & 0 & & 0 & 0 & 0 \\
\hline & $\%$ GBM & & & 67 & 0 & 33 & & 28 & 44 & 28 & & 25 & 50 & 25 & & 29 & 14 & 57 & & 60 & 30 & 10 & & 75 & 25 & 0 & & 0 & 0 & 0 & & 75 & 25 & 0 & & 0 & 0 & 0 \\
\hline GO & n GBM & 115 & 9 & 4 & 2 & 3 & 97 & 35 & 38 & 24 & 20 & 8 & 8 & 4 & 22 & 9 & 1 & 12 & 34 & 18 & 12 & 4 & 5 & 3 & 2 & 0 & 1 & 0 & 1 & 0 & 13 & 6 & 4 & 3 & 1 & 0 & 0 & 1 \\
\hline & $\%$ GBM & & $J$ & 45 & 22 & 33 & 4 & 36 & 39 & 25 & 20 & 40 & 40 & 20 & 22 & 41 & 5 & 55 & 37 & 53 & 35 & 12 & J & 60 & 40 & 0 & 1 & 0 & 100 & 0 & 10 & 46 & 31 & 23 & 1 & 0 & 0 & 100 \\
\hline GOD & $\mathrm{n}$ GBM & 10 & 1 & 0 & 0 & 1 & 12 & 0 & 4 & 8 & 7 & 1 & 1 & 5 & & 1 & 0 & 2 & & 0 & 0 & 3 & & 0 & 2 & 0 & & 0 & 0 & 0 & & 0 & 0 & 0 & & 0 & 0 & 0 \\
\hline & $\%$ GBM & & 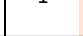 & 0 & 0 & 100 & 12 & 0 & 33 & 67 & 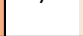 & 14 & 14 & 71 & 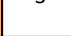 & 33 & 0 & 67 & 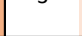 & 0 & 0 & 100 & 2 & 0 & 100 & 0 & 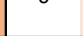 & 0 & 0 & 0 & 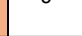 & 0 & 0 & 0 & 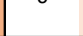 & 0 & 0 & 0 \\
\hline BGO & $\mathrm{n}$ GBM & 23 & 8 & 4 & 3 & 2 & & 10 & 4 & 4 & & 3 & 0 & 3 & & 1 & 1 & 2 & & 6 & 2 & 2 & & 0 & 0 & 0 & & 2 & 1 & 3 & & 0 & 0 & 2 & & 0 & 0 & 0 \\
\hline & $\%$ GBM & & & 44 & 33 & 22 & & 59 & 18 & 24 & & 50 & 0 & 50 & & 25 & 25 & 50 & & 60 & 20 & 20 & & 0 & 0 & 0 & & 33 & 17 & 50 & & 0 & 0 & 100 & & 0 & 0 & 0 \\
\hline
\end{tabular}


Our main general observations were:

\section{$\underline{\text { For Few-layer graphene (FLG) }}$}

- Even if FLG was quite well described in our database $(n=51)$, we did not observe any obvious trend on cytotoxicity: FLGs are both classified as cytotoxic or not.

- For $24 \mathrm{~h}$ oxidative stress, $60 \%$ of FLGs are classified as low oxidant, $30 \%$ as moderately oxidant and $10 \%$ as highly oxidant. The same trend appears for a late oxidative stress: more FLGs are classified as low or moderately toxic than highly toxic.

\section{For Graphene Oxide (GO)}

- GO does not show a specific trend concerning cytotoxicity either.

- For $24 \mathrm{~h}$ oxidative stress most GOs are classified as low oxidant (53\% of a total of 33 tested GOs) or moderately oxidant (35\%). We noticed that when functionalized with PEG, the 6 PEG-GOs in our database show a moderate to high oxidative stress ( $24 \mathrm{~h}$ exposure).

\section{$\underline{\text { For Graphene quantum dots (GQD) }}$}

- GQDs are mostly classified as highly or moderately cytotoxic.

\section{For Reduced Graphene Oxide (RGO)}

- Our database includes 23 RGOs. $58.8 \%$ of the 17 tested RGOs were classified as weakly cytotoxic at $24 \mathrm{~h}$ exposure, $17.6 \%$ as moderately toxic and $23.5 \%$ as highly toxic.

- For 24 h exposure oxidative stress, most RGOs are classified as low oxidant (60\% of 10 tested RGOs) whereas only few of them are classified as moderately or highly oxidant (respectively $20 \%$ and $20 \%$ ). 


\subsection{Investigation of potential structure-activity relationships}

Firstly, we chose to study the median size of the agglomerates in suspension measured by DLS as a relevant PCC to highlight structure-activity relationship. Indeed, this parameter seems clearly critical for oxidative stress. Figure 3 shows that whatever the GBM subfamilies considered, the higher the median size of GBM agglomerates, the higher the oxidative stress observed. The 4 GBMs classified as no/weakly oxidant are all smaller than $400 \mathrm{~nm}$ whereas among the 16 GBMs classified as highly oxidant, we have larger median size (up to $1800 \mathrm{~nm}$ ). The FLG measuring $1800 \mathrm{~nm}$ and classified as highly oxidant is functionalized with $\mathrm{COOH}$.

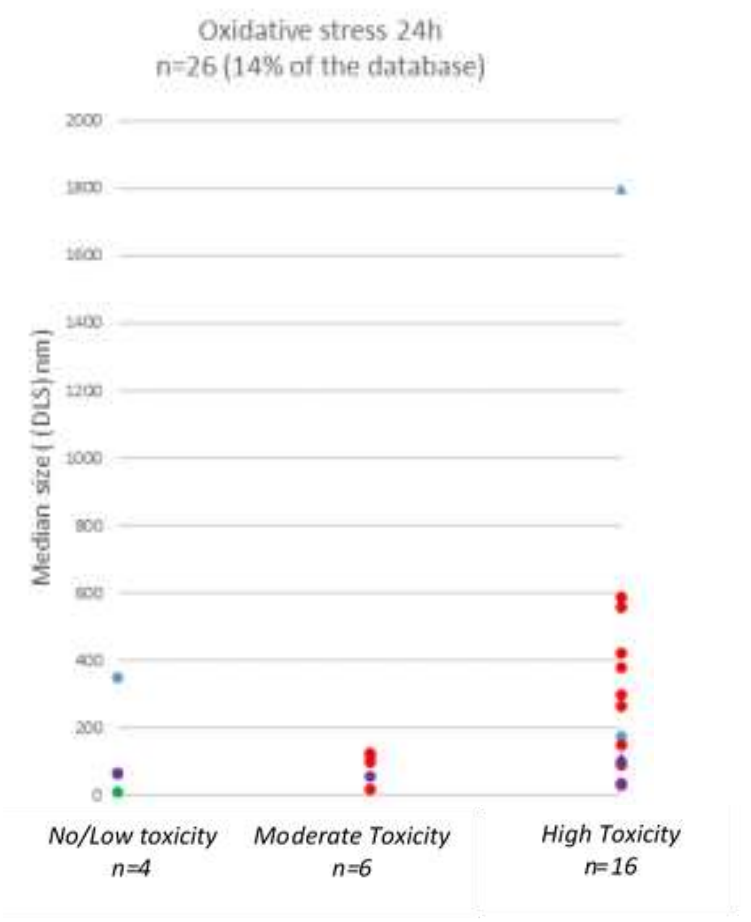

Figure 3 - Effect of median size on oxidative stress (24h exposure). 
We then considered primary particle lateral size (measured by electronic microscopy or atomic force microscopy) and observed that after a long exposure (48h), the larger FLGs (in blue) were classified as highly cytotoxic (Figure 4A).
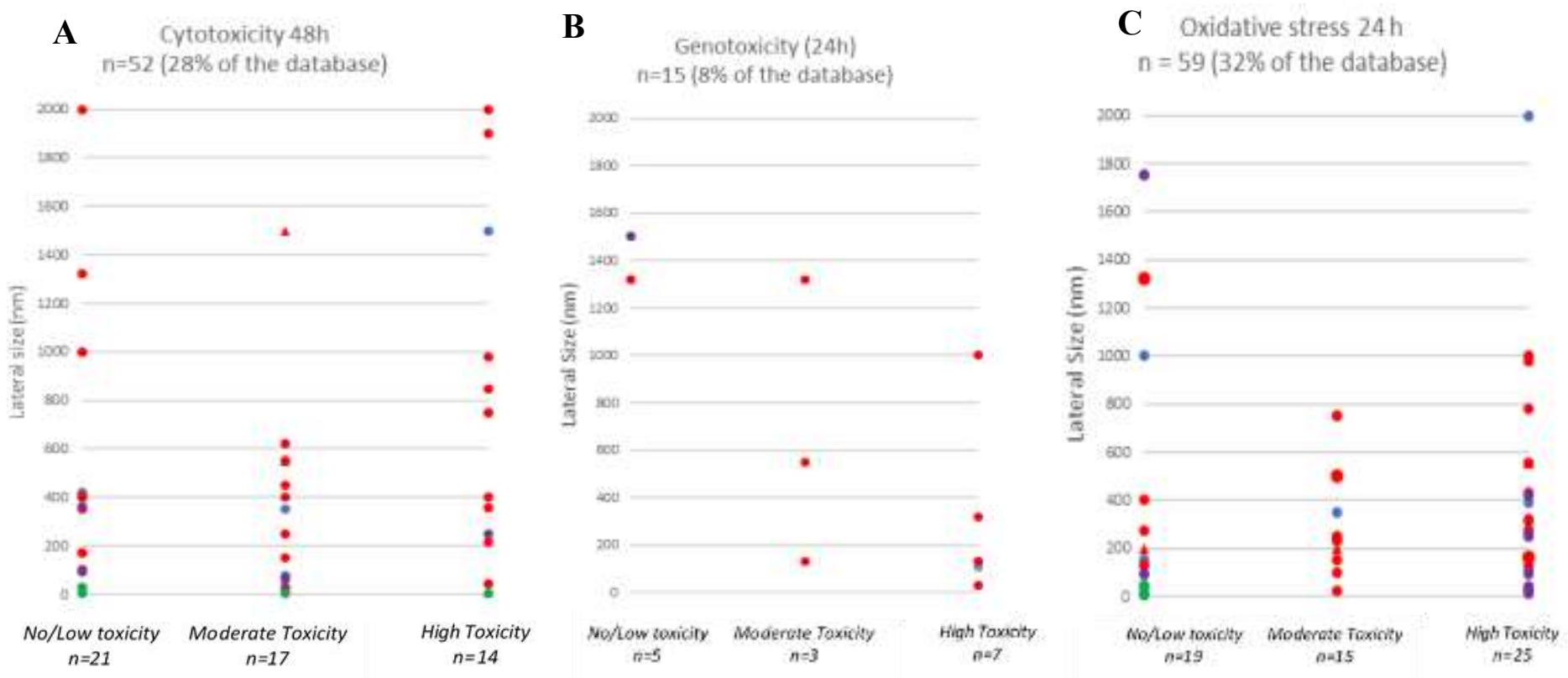

Figure 4 - Effect of lateral size below $2000 \mathrm{~nm}$ on A) cytotoxicity (48h exposure) B) genotoxicity (24h exposure) C) oxidative stress (24h exposure).

GQDs (in green) can be classified as weakly, moderately or highly cytotoxic independently of their size. Likewise, GOs (in red) are classified as low, moderately or highly cytotoxic without an obvious impact of the lateral size. A GO was functionalized with a group PEG DPSE $(1,2-$ distearoyl-sn-glycero-3-phosphoethanolamine-N-[amino(polyethylene glycol)]) and is classified as moderately cytotoxic (48h). For medium exposure ( $24 \mathrm{~h}$, Figure 4B), it appears that the smallest GBMs are classified as highly genotoxic. For a medium oxidative stress $(24 \mathrm{~h}$, Figure 4C), FLGs are mostly classified as highly oxidant, with size varying from 100 to $2000 \mathrm{~nm}$. Apart 
from one GO which measures $1320 \mathrm{~nm}$ and is classified as low-oxidant, GOs tend to become more oxidant as their size increases.

Finally, we considered the impact of the GBMs thickness (measured by AFM or XRD) on their toxicity. Thickness was often described in $\mathrm{nm}$. When it was described in "graphene stacks", we calculated the equivalence in $\mathrm{nm}$ considering that a graphene stack is approximately $0.34 \mathrm{~nm}$. This parameter appears as important for both cytotoxicity (Figure 5A) and oxidative stress (Figure 5B).
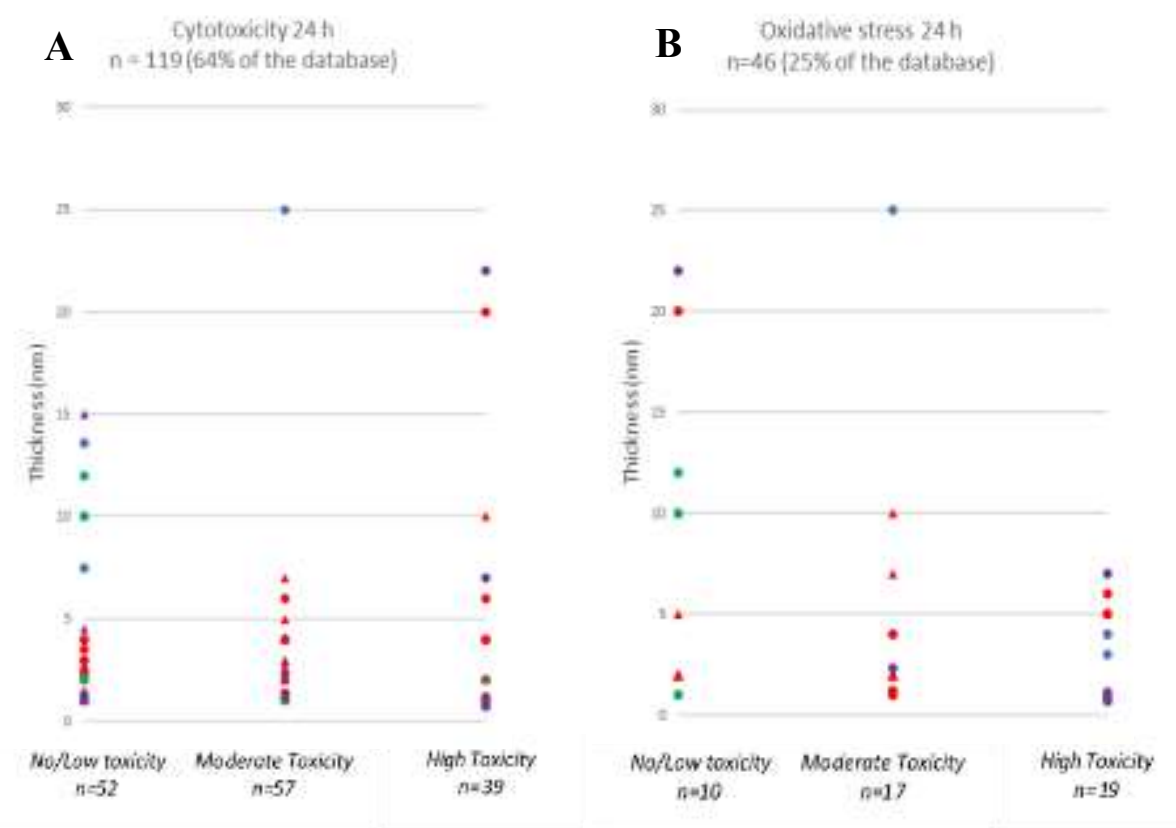

Figure 5 - Effect of thickness on A) cytotoxicity (24h exposure) B) oxidative stress (24h exposure).

Most GBMs measured less than $10 \mathrm{~nm}$ in thickness. Under that threshold it appears that the thickest GBMs are the most cytotoxic. However, if a GBM measures more than $10 \mathrm{~nm}$, it can be classified as either poorly or highly cytotoxic (Figure 5A). This threshold can be noted for 
oxidative stress: under $10 \mathrm{~nm}$, the thicker GBMs are the most oxidant. Then, all the GBMs measuring more than $10 \mathrm{~nm}$ are classified as low or moderately oxidant. Two GQDs (in green) measuring $10 \mathrm{~nm}$ and functionalized with $\mathrm{NH}_{2}$ and $\mathrm{COOH}$ groups are classified as low oxidant. A GO (in red) measuring $2 \mathrm{~nm}$ is functionalized with PEG (polyethylene glycol) and classified also as low oxidant. 3 GOs are classified as moderately oxidant and are functionalized with PEG $(5 \mathrm{~nm})$, BAS $(7 \mathrm{~nm})$ and PEI $(10 \mathrm{~nm})$ : these samples clearly increase in thickness but all show the same oxidant profile: moderate. This particular behavior might be linked to their functionalization.

\subsection{Summary of the main findings}

We could not investigate the majority of potential structure-activity relationships due to a lack of data. Many biological endpoints as well as many PCCs were not provided in most publications, as shown in Figure 2B and 2C. Furthermore, when the data were available, we did not detect a structure-activity relationship in most cases, (see S2).

As shown in Table 3, not all GBMs have the same toxicity impact. GQDs are mostly classified as highly cytotoxic. In contrary, FLGs and GOs both show a low cytotoxicity. After a short exposure time $(<12 \mathrm{~h})$, they often cause a high oxidative stress while after a medium ( $24 \mathrm{~h})$ to long ( $>48 \mathrm{~h})$ exposure time, they show a low to moderate oxidative stress.

However, the Few-layer graphene (FLG) and the Graphene Oxide (GO) (representing almost $80 \%$ of our total database and are described in almost all the publications - see Figure 2, tend to have slightly different structure-activity relationships.

The FLGs appear to show a relationship between size (agglomerates and lateral size) and thickness and genotoxicity, cytotoxicity and oxidative stress: 
- If we consider the median size of GBM agglomerate in suspension, the largest FLGs tend to show a higher oxidative stress.

- If we consider FLGs with a lateral size lower than $2000 \mathrm{~nm}$, it appears that the largest FLGs are classified as highly cytotoxic and oxidant.

- The thickness also seems to affect cytotoxicity: the thickest FLGs are classified as nontoxic when the thinnest ones are moderately or highly toxic and do not appear to affect oxidative stress.

The GOs show a relationship between size (agglomerates and lateral size) and oxidative stress.

- If we consider median agglomerate size, the largest GOs tend to cause a higher oxidative stress.

- If we consider lateral size, the largest GOs also tend to cause a higher oxidative stress.

We did not observe a clear trend between GOs thickness and cytotoxicity whereas the thickest GOs tend to show a higher oxidative stress.

\section{Discussion}

\subsection{Questioning potential structure-activity relationships of GBMs: from "one-study" scale to exhaustive review conclusions}

Our systematic review allowed us to gather 93 articles, investigating 185 GBMs, forming a quite robust database. We first investigated which GBMs were described, and their physicochemical characterization. We concluded that GO was the most investigated. This is not surprising: GOs are very promising for their biomedical applications(42) and easier to work with for toxicity assessment, as they tend to be more easily dispersible in water(43). The GBMs are often poorly 
characterized: except for lateral size and thickness, the rest of the characterization was performed for less than $50 \%$ of the GBMs of our database.

We then looked at the toxicity assessment. The toxicity assessment was carried out through the measurement of various endpoints: cytotoxicity was the most investigated which also makes sense, as it is often the first one that helps to classify the GBMs as toxic or not and gives information on the exposure concentration for further assays. The LDH, CCK-8 and MTT assay assess the cell viability / mortality for most studies. Oxidative stress is the second most investigated, as this is the major toxic pathway described for $\operatorname{GBMs}(44)$. When considering carbon-based nanomaterials, carbon radicals can be expected to play a major role in toxicity induction(45). However, their presence is rarely investigated, the oxidative stress is widely assessed through the DCFH-DA assay. The inflammation is measured with the production or the activity of cytokines such as TNF- $\alpha$, IL-6, IL-10 and IL-1 $\beta$ (Figure S3).

We highlighted trends of relationships between PCCs such as lateral size, size dispersion, thickness and biological endpoints such as cytotoxicity, oxidative stress and genotoxicity. These PCCs have previously been shown to interfere with GBM toxicity.

\subsubsection{Lateral size and size agglomerate dispersion}

Size is a critical parameter for GBM characterization. It can sometimes imply lateral size and size dispersion. However, they are distinct characteristics and need to be both characterized.

- The lateral size is mostly measured by electron microscopy or AFM. However, the choice of the method can affect the result(46). This is often the measurement of the biggest length of a single sheet of GBM. 
- The median agglomerate size, often measured by DLS, is a measurement of the GBM size agglomerates in a chosen media. It is the hydrodynamic diameter, which is calculated with the help of the Stokes-Einstein equation. Even if this measurement can easily be performed on soluble and small GBMs, some of them can represent a challenge for DLS application: the darkness of the sample can be a problem, even properly diluted, and the lack of stability can complicate this measurement.

Some size thresholds are directly linked to entry in different intracellular compartments as well as some physiological barriers for in vivo studies(47). Size of GBM dispersion affects the endocytosis(48). Size can also impact the entry in different cell compartments as well as the entry through physiological membrane(49). Lateral size can also provoke frustrated phagocytosis, which can only be observed in specific cell types (such as macrophages or dendritic cells) for an in vitro study.

Size of GBM is involved in various modes of action and is a crucial GBM characteristic. However, some papers have opposite conclusions when it comes to size impact on GBM toxicity. For example, De Gurunathan et al. (50) measured the toxicity impact of GO measuring respectively $20 \mathrm{~nm}$ and $100 \mathrm{~nm}$ (measured by DLS and TEM). It appeared that the smallest GO had also the highest impact on both TM3 and TM4 cells. In contrast, Jia et al.(25) studied different types of GBMs with sizes of approximately 30,300 and $1000 \mathrm{~nm}$ (measured by DLS and AFM). For survival rates of HEK 293T, the smallest and the largest GBMs appear to have a more toxic effect.

In our review, even if we were not able to spot an indisputable relationship between size and biological impacts, we highlighted size as a relevant characteristic impacting GBMs toxicity. However, the specificities of this relationship remain blurred depending on the size range as well 
as the studied endpoint: we found that an increasing lateral size decreased early oxidative stress as well as genotoxicity ( $24 \mathrm{~h}$ post exposure) while appearing to increase oxidative stress for a medium exposure (24h). Meanwhile, the agglomerate size (measured by DLS) shows different patterns: if it increases, it increases both oxidative stress and genotoxicity.

Genotoxicity caused by GBMs is widely mediated by oxidative stress(51). It might then seem surprising that genotoxicity and oxidative stress do not have the same relationship with lateral size. In addition, early and medium oxidative stress do not follow the same trend. The early and late oxidative stress can be integrated into different modes of action. Indeed, mitochondriamediated apoptosis can be mediated by oxidative stress, while causing the release of reactive oxygen species.

\subsubsection{Oxidation}

Surface oxidation is a capital information to classify GBM and is relevant to influence its toxicity by affecting its dispersibility in cell culture media(52) as well as its distribution in the body. Oxidation also modifies surface chemical structure of GBMs and conditions numerous adverse effects such as membrane damage, lipid peroxidation that can lead to cytotoxicity (53) on pulmonary cells as well as skin cells(54).

The observation of cytotoxicity, oxidative stress or genotoxicity depending on the GBM type (Table 3) do not allow us to highlight a specific impact: GOs do not show more or less toxicity compared to FLGs which are less oxidized. Moreover, the oxidation state is characterized for only $32 \%$ of the GBMs from the database. Therefore, our study of the relationship between oxidation and biological effects was not conclusive. 


\subsubsection{Thickness}

Thickness is an important characteristic of GBMs that can guide their classification. Flawless graphene should be only one atom thick, which means it should be about $1 \mathrm{~nm}$ thick, though most studied GBMs are at least few layers thick. We found that thickness was reported for only $61 \%$ of our total database. Beyond classifying GBMs, thickness is a capital characteristic for toxicity as it influences its distribution. Indeed, thin GBMs show an easier urinary excretion, allowing an elimination whereas larger GBMs are more likely to remain in organs such as liver and spleen(55). We observed an increased cytotoxicity and oxidative stress with increasing thickness. However, this increase is only clear for GBMs measuring $10 \mathrm{~nm}$ at most. Some large GBMs are classified as no or poorly toxic. It might indicate that after that threshold of approximately $10 \mathrm{~nm}$, the in vitro toxic effects are inhibited since the GBMs might not be internalized, stopping the toxic pathway of some GBMs whereas others will cause toxic damage to cells even without being internalized.

\subsubsection{Structure-activity relationship of GBMs: what can systematic reviews bring to light?}

In 2015, Bussy et al.(56) published a data mining work. Their article introduced the available literature in an innovative presentation of a 3D axis plot, focusing on GBMs physicochemical characteristics-toxicity relationship. The results showed a clear lung toxicity and a pattern of toxicity depending on the graphene type. One of the major conclusions of this paper was that more in vivo research was needed, as well as an appropriate characterization of the materials. Many toxicity assessments were done since 2015 and we aimed to fill some data gaps that existed 
few years ago when GBMs' toxicity study, as well as its physicochemical characterization, was still poorly explored.

When we started to work on this review, we expected that the high quantity of data available would allow us to point out which characteristics could affect GBM's toxicity and we were looking forward to having a clearer insight of structure-activity relationship of GBMs. Even if we were able to spot some trends of relationship between biological effects and physicochemical characteristics, our main conclusion is that with the actual state of the literature, and with our methodology, we cannot bring to light specific structure-activity relationships of GBMs. Nor can we explain how one PCC can influence the graphene's toxicity.

As we discussed above, even if the leading paradigm is that PCCs probably have an influence on GBM's toxicity, these relationships appear to be complex. Beyond knowing which characteristics have an impact on GBMs toxicity, it is crucial that we disentangle these relationships to build safer-by-design GBMs.

Many evidence lead us to assume that PCCs may have an impact on nanomaterials, and more specifically GBMs’ toxicity.

Most reviews report that lateral size, thickness, oxidation(57), specific surface area(58), dispersion, surface charge and chemistry(59-61), size ratio(30) and impurities(62) can influence GBMs' toxicity through different modes of action briefly represented in Figure 6. Oxidative stress, mitochondria mediated apoptosis, autophagy(63), lysis of the cells(64) and frustrated phagocytosis(65) are all well described GBMs toxicity pathways. It is worth noting that the observations will dramatically vary depending on the model. In vivo models allow us a global overview of the toxic impacts and physiological endpoints at an organism scale (such as excretion) whereas in vitro studies can help highlighting specific modes of action for a closer 
look on the biological mechanisms involved. Moreover, some studies explored several GBMs varying by only one PCC, highlighting their specific toxicity impact. Zhang et al.(47) studied 3 GOs with increasing oxidation but with the same size and thickness. It appears that the less oxidized GOs have a stronger impact on cytotoxicity and oxidative stress on MEFs (mouse embryo fibroblasts) cells.

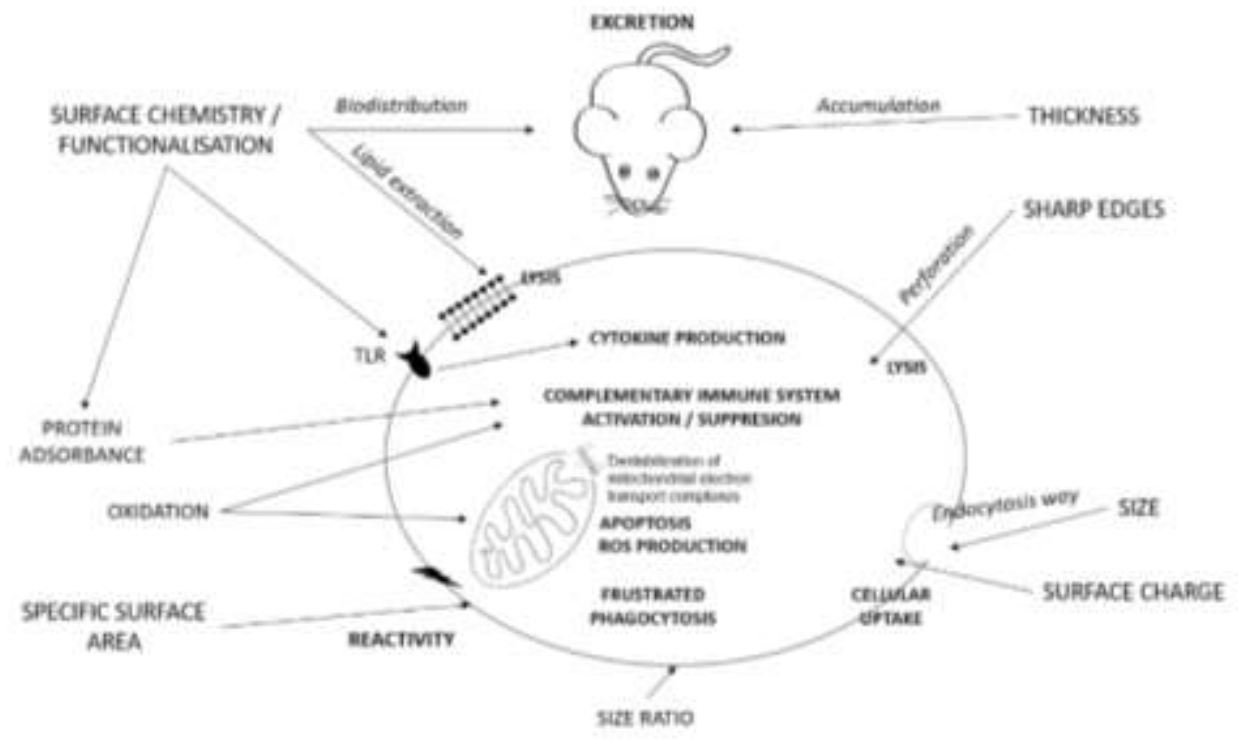

Figure 6 - Schematic representation of potential structure-activity relationships of graphenebased materials.

Oxidative stress, mitochondria mediated apoptosis, autophagy(63), lysis of the cells(64) and frustrated phagocytosis(65) are all well described GBMs toxicity pathways.

Based on such publications, many reviews state that size, oxidation state, thickness; among other PCCs have an impact on the biological effects of GBMs. However, to our knowledge, we could not find a review article that linked a specific PCC with a biological impact by gathering the available literature. Moreover, various modes of action of GBMs are thoroughly investigated. 
Yet the absence of specificities concerning the type of GBMs when studying these can be an obstacle for finding mechanistic explanations for structure-activity relationships.

\subsection{Why we could not highlight clear structure-activity relationship for GBMs and how to fix it}

It is very likely that we did not clearly spot potential relationships due to two factors: the lack of physicochemical characterization and insufficient and non-standardized toxicity assessments.

\subsubsection{Lack of physicochemical characterization}

As described above, GBMs were generally not characterized, which decreased our capacity to spot relationships between characteristics and biological activity.

GBM characterization should be standardized and adapted to nanomaterials, as well as integrated into the toxicity assessment process. A minimal characterization is required in a regulatory framework(66): dose (given in mass, particle number and surface area), physical form (implying size, agglomeration state) and chemical form (surface charge and chemistry). These characteristics should be investigated pre and post exposure. In an outlook based on the OECD testing program, Rasmussen et al.(67) advised to carefully characterize at the very least size (and size distribution) and surface functionalization.

Untangling the relationship between characteristics and toxicity for GBMs implies that we have enough information concerning characteristics that could affect toxicity. Assessing lateral size, size dispersion, specific surface area, thickness, surface oxidation and impurities is required for GBM toxicity assessment. 
The particular properties of nanomaterials can make characterization challenging but several methods are available(68) to assess as exactly as possible the needed characteristics (Table 5).

Table 5 - Necessary physicochemical characterization and relevant methods. EM: Electron microscopy, AFM: Atomic Force Microscopy, DLS: Dynamic Light Scattering, TEM : Transmission electron microscopy, SEM : Scanning electron microscopy, BET: Brunauer, Emmett and Teller, XRD: X-Ray Diffraction, XPS: X-Ray Photoelectron Spectrometry, EDX: Energy-Dispersive X-ray spectroscopy, ICP: Inductively Coupled Plasma spectrometry.

\begin{tabular}{|c|c|}
\hline CHARACTERISTIC & METHOD \\
\hline \multirow{2}{*}{ Lateral Size } & EM \\
& AFM \\
\hline \multirow{2}{*}{ Size dispersion in media } & DLS \\
& Cryo-TEM/SEM \\
& AFM \\
\hline Specific surface area & BET \\
\hline \multirow{2}{*}{ Thickness } & AFM \\
& RAMAN \\
& XRD \\
\hline \multirow{2}{*}{ Surface oxidation } & XPS \\
& EDX \\
\hline Impurities & ICP \\
\hline
\end{tabular}

It is also crucial that the characteristics are in accordance with the exposure solution of the toxicity testing. For instance, measurement of lateral size should be done on a properly dispersed GBM, with the same dispersion protocol than the preparation of the exposure solutions for toxicity assessment. The point is to characterize, as much as possible, the same GBM that the cells will be exposed to. The dispersion protocol, and more importantly when the GBM is sonicated, can have a major impact on some characteristics such as lateral size(69). Lastly, the dispersion media 
can have a dramatic impact on the aggregation state of $\operatorname{GBMs}(70)$, which can lead to a different toxic impact.

Therefore, it is crucial to characterize the GBMs in relevant exposure conditions as much as possible. In this review, we chose to study independently each PCC to simplify this work and be able to manage an important amount of data. However, we know that some GBMs PCCs are directly correlated with each other. The correlation between physicochemical characteristics (or descriptors) is a major issue and needs to be considered in the construction of a structure-activity relationship model(71,72). However, with the restricted amount of available data, it is very difficult to study and quantify these correlations. Lastly, it is important to take into account that the variation of a PCC must be wide to conclude on any structure-activity relationship. For example, our database included GBMs with lateral size between $5 \mathrm{~nm}$ and $10000 \mathrm{~nm}$. Hence, it is only possible to conclude on the nanomaterials in this size range.

\subsubsection{Insufficient and non-standardized toxicity assessment}

The choice of working on animals or cells is obviously an important aspect of a toxicity assessment design. In a context where scientists are asked to reduce the animal experiments(73), in vitro assessment is often considered as the best approach for early testing and screening. For in vitro studies, human cells are sometimes considered as the most relevant to mimic a human exposure and a human health effect. Even if this approach is wise, one must be aware that even with a relevant model, it is very difficult to approximate an in vivo exposure through an in vitro assessment. Some models exist(74) and are promising but could currently be insufficient in a regulatory framework. New models such as reconstructed epithelium are raising interest in the nanotoxicity field: they can model skin or pulmonary epithelium. Even if they have undeniable 
assets and can accurately represent an exposition without the need of animal testing, they can also be a little difficult to manage and maintain, as well as being quite expensive. These assays can also be difficult to interpret and compare to the results from other models: the exposure dose is expressed as $\mathrm{mg} / \mathrm{cm}^{2}$ and is often difficult to convert in $\mu \mathrm{g} / \mathrm{mL}(75)$. On the other hand, animal cells can be a cheap, stable alternative for a screening purpose.

Then, one must decide to use a cell line model that suits the most the expected exposure. Some nanomaterials are integrated in cosmetics while others are present is the air pollution: it is only logical to use the appropriate cell model for each of them. The exposure pathway of GBMs is mostly respiratory(76). Hence, choosing respiratory cell lines is a relevant option. It can also be suitable to choose a ubiquitous cell that can be involved from the very beginning of the mode of action of GBMs, such as immune cells. Macrophages, for example, can be an interesting choice as they are nonspecific cells that are likely to be among the first cells encountering GBMs once they enter the organism. Moreover, in a standardization process, one should note that some cells are more common than others. Comparing results from different cell lines can be challenging. The same GBMs tested on Caco-2 and A549 will show no response even at high dose (100 $\mu \mathrm{g} / \mathrm{mL})$ for Caco-2 whereas it will cause cytotoxicity from the smallest dose $(10 \mu \mathrm{g} / \mathrm{mL})$ for A549(77). When tested with BEAS-2B and A549, the same GBMs will show a greater toxicity to A549 cells(78). Overall, the choice of a cell line can deeply affect the toxicity response. Gies and Zhou have shown that adherent cell lines (NIH 3T3, U87 and A549) showed the least change in proliferation as a response to GO while the semi-adherent cell line, RAW 264.7, showed moderate change and the suspension cell lines (white blood cells), NB4 and HL 60, showed the greatest response(79). 
Considering acellular methods as a part of the toxicity assessment of nanomaterials can also be an interesting option and avoid some of the inevitable variations caused by cellular assays. Some of them can give information on the oxidative potential of $\operatorname{GBMs}(80)$, which is useful since the GBM toxicity pathway involves oxidative potential. Moreover, it would enable more assays, without increasing the cost and with only few time and organization needed. Combining acellular and cellular toxicity assessment can be a great option to increase the available data of GBMs while maintaining a reasonable commitment in experiments.

Once settled on a model, one must choose the endpoint to measure and the appropriate assay $(81,82)$. The in vitro toxicity assessment of GBMs often stands on the measurement of cell viability, oxidative stress, inflammation and genotoxicity. One should choose the desired endpoint depending on the GBM supposed mode of action. There are often many kinds of assays to assess one biological endpoint. In our selected publications, the mortality / viability endpoint was assessed with almost 20 different assays. These assays can measure different kinds of biological reaction, which can blur and make analysis more challenging.

Bias and interferences are a well-known problematic in toxicology assessment Many GBMs are very dark, which can cause optic bias. This optic bias must be measured in order to be corrected on the final results. Moreover, GBMs can be suspected to interfere with some assays. Before using an assay, it is wise to search the literature for interferences. If one wants to perform this assay even if some interferences are reported, it is necessary to perform interferences studies first. For example, MTT has been reported to possibly interfere with GBMs. However, this assay was used for toxicity assessment after being searched for interferences, without finding any(83). As we explained in introduction, the GBM family is extremely wide and includes various materials: some conclusions concerning a specific GBM is not always applicable to the whole family. 
Moreover, a proper study of endotoxin must be done in order to make sure that the toxicity impact is not linked to a possible contamination. Endotoxin study can be done with different assays for GBMs but a work from Mukherjee et al. pointed out that GBMs could interfere with some of these assays and proposed an assay based on macrophages that can be used for all $\operatorname{GBMs}(85)$.

Overall, it is necessary to question the bias and interference problematic before using any kind of assay.

Once the assay chosen, the final point to decide is the exposure concentration of the tested GBMs and the exposure time. The in vitro exposure concentrations can range from under $5 \mu \mathrm{g} / \mathrm{mL}$ to $200 \mu \mathrm{g} / \mathrm{mL}$. It would be difficult to settle on precise necessary exposure concentrations. However, it is crucial to test at least 3 different concentrations from $10 \mu \mathrm{g} / \mathrm{mL}$ to $100 \mu \mathrm{g} / \mathrm{mL}$. It is the minimum required to have an insight of the possible dose-response relationship of the tested material(84). When assessing an endpoint, some studies did measure the toxic response for only one or two concentrations of GBMs, leaving many uncertainties, which might lead to wrong classification of toxicity. Exposure time depends on the tested endpoint. Some biological responses need up to 24 hours to be observed, such as RNA expression whereas some are very fast. For purposes of standardization, one should integrate at least a 24-hour exposure time to each assay, when it is relevant.

The preparation of chosen nanoparticles is another essential step, especially for insoluble materials such as carbon-based particles. Considering dispersion and formation of protein corona is wise for any toxicity assessment and can help understanding the involved internalization mechanisms. Choosing the right dispersion protocol can be challenging. However, a method (72) can help ensuring a stable dispersion and a more efficient internalization of tested GBMs. 
Lastly, the choice of GBMs to test is also critical. For example, the lateral size of the vast majority our GBMs database is under $2000 \mathrm{~nm}$ (Figure 34). Hence, we were not able to highlight valid structure-activity relationship for GBMs that have a lateral size above $2000 \mathrm{~nm}$. Testing a wide range of GBMs would allow the scientific community to have an extensive insight of the relationship between a PCC and a biological endpoint.

\subsection{Suggestions for standardization of GBMs toxicity assessment}

Figure 7 introduces some recommendations for a relevant structure-activity study on GBMs.

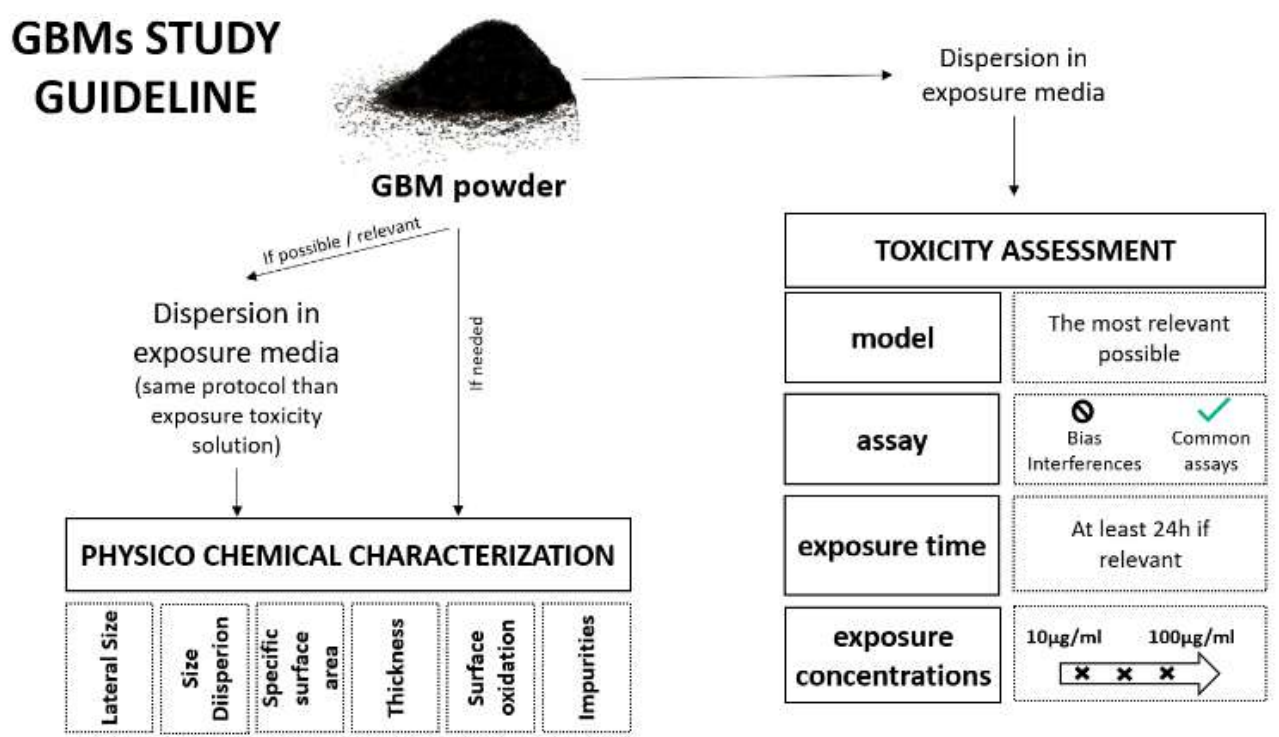

Figure 7 - GBMs' toxicity assessment guideline.

Starting the toxicity assessment of GBMs, one must keep in mind a few simple guidelines. Toxicity assessment must be done on the model which is considered as the most relevant possible depending on the context of the research as described above. The assays must be chosen carefully, and bias and interferences must be considered. The exposure time and concentrations must be as wide as possible: a good start would be to expose the model to GBMs at least 24 hours (if this is 
in agreement with the biological endpoint) and at least 3 different concentrations between 10 $\mu \mathrm{g} / \mathrm{mL}$ and $100 \mu \mathrm{g} / \mathrm{mL}$. Concerning physicochemical characterization, lateral size, size dispersion, specific surface area, thickness, surface oxidation and impurities should be assessed, in agreement with most regulatory guidelines (ISO 10808:2010). The characterization methods should also be chosen carefully (see Table 5), taking into account their feasibility and relevance. If possible, one should perform these characterizations on GBMs that are prepared with the same protocol than the ones used for toxicity assessment.

Another important point for studying SARs is the variety of the chosen GBMs. The choice of the studied GBMs is critical to make sure our conclusions can be applied to the majority of the GBMs that might be used in the next years. We observed that the most studied GBMs are GO or FLGs, often measuring less than $1 \mu \mathrm{m}$ in lateral size (mean size of $900 \mathrm{~nm}$ for our database) and less than $5 \mathrm{~nm}$ in thickness (mean thickness of $3.4 \mathrm{~nm}$ for our database).

These samples are obviously important. However, their representation in the toxicity studies might not be consistent with the reality of the incoming GBMs market. When it comes to GBMs application, the electronic and thermal properties are particularly sought. RGOs, for example, show better electronic and thermal properties compared to GO (86).

It might be time to consider studying GBMs considering their potential future impact on the global market and consider studying other GBMs such as RGOs or GNPs

\section{Conclusions}

This analysis aimed to provide an insight into the available literature exploring GBMs toxicity in 2021 and attempted to spot potential relationships between GBMs PCCs and their toxicity. We extracted data from 93 papers, representing 185 GBMs. Some conclusions can be drawn: (i) we 
highlighted that RGOs are often classified as low oxidant and low cytotoxic, (ii) GQDs are mainly classified as moderately or highly cytotoxic. However, these GBMs were not studied enough to enable us to spot any clear structure-activity relationships. Besides, the GOs and FLGs are the most studied GBMs and represent $80 \%$ of our database. (iii) For FLGs, we spotted a relationship between median size and oxidative stress, between lateral size and both cytotoxicity and oxidative stress and between thickness and cytotoxicity. (iv) For GOs, we spotted relationships between PCCs such as median size, lateral size and thickness and a biological endpoint: oxidative stress. Nevertheless, we were not able to highlight structure-activity relationships for most PCCs and biological endpoints. Overall, these conclusions do not allow us to provide specific enough relationship to suggest a model of safer-by-design GBM. It is very likely that we did not clearly show potential relationships due to the absence of standardization for toxicity assessment as well as an inadequate physicochemical characterization of GBMs. The exponential growth of demand for nanomaterials urges us to acquire and gather a large amount of toxicity data, which should lead us to consider scientific collaboration as the only way of achieving this tremendous work. When working, one must keep in mind that scientific colleagues might use their data to reach a next step in GBM's toxicity assessment. Making our hard work as exploitable as possible by optimizing and standardizing our toxicity protocol is crucial.

\section{List of abbreviations}

(Q)SAR: Quantitative structure-activity relationship

2D: 2 dimensions 
3D: 3 dimensions

3R: Reduce, replace, refine

AFM: Atomic force microscopy

CCK-8: Cell Counting Kit-8

DCFH-DA: Dichloro-dihydro-fluorescein diacetate

DLS: Dynamic light scattering

GBMs: Graphene-based materials

GOs: Graphene Oxides

GQDs: Graphene quantum dots

IL-10 : Interleukin 10

IL-1 $\beta$ : Interleukin $1 \beta$

IL-6 : Interleukin 6

LDH: Lactate dehydrogenase.

MTT: 3-(4,5-dimethylthiazol-2-yl)-2,5-diphenyltetrazolium bromide

PCCs: Physicochemical characteristics

PEG: Polyethylene glycol

PEG-DSPE: $\quad$ 1,2-distearoyl-sn-glycero-3-phosphoethanolamine-N-[amino(polyethylene glycol)])

FLGs: Few-layer graphenes

rGOs: Reduced graphene oxides

RNA: Ribonucleic acid

ROS: reactive oxygen species

TEM: Transmission electron miscroscopy 
TNF- $\alpha$ : Tumor necrosis factor alpha

\section{Funding}

This research did not receive any specific grant from funding agencies in the public, commercial, or not-for-profit sectors.

\section{Competing interests}

Salma Achawi and Bruno Feneon are employees of Michelin company, a global tire and rubber goods manufacturer.

Supporting information: S1) Attribution of toxicity score. S2) 2D graphs that do not highlight an obvious structure-activity relationship. S3) Assays used for major endpoints in in vitro studies. S4) References of the publications included in the database.

\section{References}

1. Novoselov KS. Electric Field Effect in Atomically Thin Carbon Films. Science (80- ). 2004;306(5696):666-9.

2. Wick P, Louw-Gaume AE, Kucki M, Krug HF, Kostarelos K, Fadeel B, et al. Classification Framework for Graphene-Based Materials. Angew Chemie Int Ed. 2014;53(30):7714-8.

3. Cai M, Thorpe D, Adamson DH, Schniepp HC. Methods of graphite exfoliation. J Mater Chem. 2012;22(48):24992. 
4. Arthi G PB, Bd L. A Simple Approach to Stepwise Synthesis of Graphene Oxide Nanomaterial. J Nanomed Nanotechnol. 2015 Jul 2;06(01)

5. Zainuddin MF, Nik Raikhan NH, Othman NH, Abdullah WFH. Synthesis of reduced Graphene Oxide (rGO) using different treatments of Graphene Oxide (GO). IOP Conf Ser Mater Sci Eng. 2018;358:12046.

6. Bacon M, Bradley SJ, Nann T. Graphene Quantum Dots. Part Part Syst Charact. 2014;31(4):415-28.

7. Lee C, Wei X, Kysar JW, Hone J. Measurement of the Elastic Properties and Intrinsic Strength of Monolayer Graphene. Science (80- ). 2008;321(5887):385-8.

8. Dasari Shareena TP, McShan D, Dasmahapatra AK, Tchounwou PB. A Review on Graphene-Based Nanomaterials in Biomedical Applications and Risks in Environment and Health. Nano-Micro Lett. 2018 Nov 18;10(3). Available from: http://link.springer.com/10.1007/s40820-018-0206-4

9. Ijeomah G, Samsuri F, Obite F, Zawawi MAM. Recent advances in chemical functionalisation of graphene and sensing applications. Int J Biomed Nanosci Nanotechnol. 2020;4(1/2):1.

10. Ali I, Alharbi OML, Tkachev A, Galunin E, Burakov A, Grachev VA. Water treatment by new-generation graphene materials: hope for bright future. Environ Sci Pollut Res. 2018;25(8):7315-29.

11. Shin SR, Li Y-C, Jang HL, Khoshakhlagh P, Akbari M, Nasajpour A, et al. Graphenebased materials for tissue engineering. Adv Drug Deliv Rev. 2016;105:255-74.

12. Tabish TA. Graphene-based materials: The missing piece in nanomedicine? Biochem Biophys Res Commun. 2018;504(4):686-9. 
13. Novoselov KS, Fal'ko VI, Colombo L, Gellert PR, Schwab MG, Kim K. A roadmap for graphene. Nature. 2012;490(7419):192-200.

14. Groso A, Petri-Fink A, Magrez A, Riediker M, Meyer T. Management of nanomaterials safety in research environment. Part Fibre Toxicol. 2010;7(1):40.

15. Iavicoli I, Leso V, Piacci M, Cioffi DL, Guseva Canu I, Schulte PA. An Exploratory Assessment of Applying Risk Management Practices to Engineered Nanomaterials. Int J Environ Res Public Health. 2019;16(18):3290.

16. ANSES. Development of a specific Control Banding Tool for Nanomaterials Report. 2010;

17. Riediker M, Ostiguy C, Triolet J, Troisfontaine P, Vernez D, Bourdel G, et al. Development of a Control Banding Tool for Nanomaterials. J Nanomater. 2012;2012:18.

18. Farjadian F, Ghasemi A, Gohari O, Roointan A, Karimi M, Hamblin MR. Nanopharmaceuticals and nanomedicines currently on the market: challenges and opportunities. Nanomedicine. 2019;14(1):93-126.

19. Dekkers S, Oomen AG, Bleeker EAJ, Vandebriel RJ, Micheletti C, Cabellos J, et al. Towards a nanospecific approach for risk assessment. Regul Toxicol Pharmacol. 2016;80:46-59.

20. Arts JHE, Irfan M-A, Keene AM, Kreiling R, Lyon D, Maier M, et al. Case studies putting the decision-making framework for the grouping and testing of nanomaterials (DF4nanoGrouping) into practice. Regul Toxicol Pharmacol. 2016;76:234-61.

21. Kraegeloh A, Suarez-Merino B, Sluijters T, Micheletti C. Implementation of Safe-byDesign for Nanomaterial Development and Safe Innovation: Why We Need a Comprehensive Approach. Nanomaterials. 2018;8(4):239. 
22. Schwarz-Plaschg C, Kallhoff A, Eisenberger I. Making Nanomaterials Safer by Design? Nanoethics. 2017;11(3):277-81.

23. Duch MC, Budinger GRS, Liang YT, Soberanes S, Urich D, Chiarella SE, et al. Minimizing Oxidation and Stable Nanoscale Dispersion Improves the Biocompatibility of Graphene in the Lung. Nano Lett. 2011;11(12):5201-7.

24. Chatterjee N, Eom H-J, Choi J. A systems toxicology approach to the surface functionality control of graphene-cell interactions. Biomaterials. 2014;35(4):1109-27.

25. Jia P-P, Sun T, Junaid M, Yang L, Ma Y-B, Cui Z-S, et al. Nanotoxicity of different sizes of graphene $(\mathrm{G})$ and graphene oxide $(\mathrm{GO})$ in vitro and in vivo. Environ Pollut. 2019;247:595-606.

26. Chang Y, Yang ST, Liu JH, Dong E, Wang Y, Cao A, et al. In vitro toxicity evaluation of graphene oxide on A549 cells. Toxicol Lett. 2011 Feb 5;200(3):201-10. Available from: https://pubmed.ncbi.nlm.nih.gov/21130147/

27. Russier J, Treossi E, Scarsi A, Perrozzi F, Dumortier H, Ottaviano L, et al. Evidencing the mask effect of graphene oxide: A comparative study on primary human and murine phagocytic cells. Nanoscale. 2013 Nov 21;5(22):11234-47. Available from: https://pubmed.ncbi.nlm.nih.gov/24084792/

28. Vranic S, Rodrigues AF, Buggio M, Newman L, White MRH, Spiller DG, et al. Live Imaging of Label-Free Graphene Oxide Reveals Critical Factors Causing OxidativeStress-Mediated Cellular Responses. ACS Nano. 2018 Feb 27;12(2):1373-89. Available from: https://pubmed.ncbi.nlm.nih.gov/29286639/

29. Yoon OJ, Kim I, Sohn IY, Kieu TT, Lee NE. Toxicity of graphene nanoflakes evaluated by cell-based electrochemical impedance biosensing. J Biomed Mater Res - Part A. 
2014;102(7):2288-94. Available from: https://pubmed.ncbi.nlm.nih.gov/23894129/

30. De Marzi L, Ottaviano L, Perrozzi F, Nardone M, Santucci S, De Lapuente J, et al. Flake size-dependent cyto and genotoxic evaluation of graphene oxide on in vitro A549, CaCo2 and vero cell lines. J Biol Regul Homeost Agents. 2014;28(2):281-9.

31. Ma J, Liu R, Wang X, Liu Q, Chen Y, Valle RP, et al. Crucial Role of Lateral Size for Graphene Oxide in Activating Macrophages and Stimulating Pro-inflammatory Responses in Cells and Animals. ACS Nano. 2015 Sep 21;9(10):10498-515. Available from: https://pubmed.ncbi.nlm.nih.gov/26389709/

32. Frontiñán-Rubio J, Victoria Gómez M, Martín C, González-Domínguez JM, Durán-Prado M, Vázquez E. Differential effects of graphene materials on the metabolism and function of human skin cells. Nanoscale. 2018 Jun 28;10(24):11604-15. Available from: https://pubs.rsc.org/en/content/articlehtml/2018/nr/c8nr00897c

33. Zhang W, Yan L, Li M, Zhao R, Yang X, Ji T, et al. Deciphering the underlying mechanisms of oxidation-state dependent cytotoxicity of graphene oxide on mammalian cells. Toxicol Lett. 2015;237(2):61-71.

34. Chatterjee N, Yang JS, Park K, Oh SM, Park J, Choi J. Screening of toxic potential of graphene family nanomaterials using in vitro and alternative in vivo toxicity testing systems. Environ Health Toxicol. 2015 Jul 15;30:e2015007. Available from: https://pubmed.ncbi.nlm.nih.gov/26602558/

35. Li J, Zhang X, Jiang J, Wang Y, Jiang H, Zhang J, et al. Systematic assessment of the toxicity and potential mechanism of graphene derivatives in vitro and in vivo. Toxicol Sci. 2019 Jan 1;167(1):190-201. Available from: https://pubmed.ncbi.nlm.nih.gov/30239936/

36. Li Y, Feng L, Shi X, Wang X, Yang Y, Yang K, et al. Surface coating-dependent 
cytotoxicity and degradation of graphene derivatives: Towards the design of non-toxic, degradable nano-graphene. Small. 2014 Apr 24;10(8):1544-54. Available from: https://pubmed.ncbi.nlm.nih.gov/24376215/

37. Matesanz MC, Vila M, Feito MJ, Linares J, Gonçalves G, Vallet-Regi M, et al. The effects of graphene oxide nanosheets localized on F-actin filaments on cell-cycle alterations. Biomaterials $\quad 2013 \quad$ Feb;34(5):1562-9. Available from: https://pubmed.ncbi.nlm.nih.gov/23177613/

38. Xu M, Zhu J, Wang F, Xiong Y, Wu Y, Wang Q, et al. Improved In Vitro and In Vivo Biocompatibility of Graphene Oxide through Surface Modification: Poly(Acrylic Acid)Functionalization is Superior to PEGylation. ACS Nano . 2016 Mar 22 ;10(3):3267-81. Available from: https://pubs.acs.org/doi/abs/10.1021/acsnano.6b00539

39. Xie Y, Wan B, Yang Y, Cui X, Xin Y, Guo LH. Cytotoxicity and autophagy induction by graphene quantum dots with different functional groups. J Environ Sci (China). 2019 Mar 1;77:198-209.

40. Donaldson K, Murphy FA, Duffin R, Poland CA. Asbestos, carbon nanotubes and the pleural mesothelium: A review of the hypothesis regarding the role of long fibre retention in the parietal pleura, inflammation and mesothelioma. Vol. 7, Particle and Fibre Toxicology. Part Fibre Toxicol; 2010. Available from: https://pubmed.ncbi.nlm.nih.gov/20307263/

41. Lin L-S, Bin-Tay W, Aslam Z, Westwood AVK, Brydson R. Determination of the lateral size and thickness of solution-processed graphene flakes. J Phys Conf Ser. 2017;902:12026.

42. Singh DP, Herrera CE, Singh B, Singh S, Singh RK, Kumar R. Graphene oxide: An 
efficient material and recent approach for biotechnological and biomedical applications. Mater Sci Eng C. 2018;86:173-97.

43. Neklyudov V V, Khafizov NR, Sedov IA, Dimiev AM. New insights into the solubility of graphene oxide in water and alcohols. Phys Chem Chem Phys. 2017;19(26):17000-8.

44. Jarosz A, Skoda M, Dudek I, Szukiewicz D. Oxidative Stress and Mitochondrial Activation as the Main Mechanisms Underlying Graphene Toxicity against Human Cancer Cells. Oxid Med Cell Longev. 2016;2016:1-14.

45. R L, LM G, CH C, ND M, Z J, X W, et al. Surface Oxidation of Graphene Oxide Determines Membrane Damage, Lipid Peroxidation, and Cytotoxicity in Macrophages in a Pulmonary Toxicity Model. ACS Nano . 2018 Feb 27 ;12(2):1390-402. Available from: https://pubmed.ncbi.nlm.nih.gov/29328670/

46. Liu Z, Liu W, Xie X, Zhao W, Wen Y, Wang Q, et al. Lateral Size of Graphene Characterized by Atomic Force Microscope. IOP Conf Ser Earth Environ Sci. 2019;252:22022.

47. Zhang X, Yin J, Peng C, Hu W, Zhu Z, Li W, et al. Distribution and biocompatibility studies of graphene oxide in mice after intravenous administration. Carbon $\mathrm{N} \mathrm{Y}$. 2011;49(3):986-95.

48. Mendes RG, Mandarino A, Koch B, Meyer AK, Bachmatiuk A, Hirsch C, et al. Size and time dependent internalization of label-free nano-graphene oxide in human macrophages. Nano Res. 2017;10(6):1980-95.

49. Ou L, Song B, Liang H, Liu J, Feng X, Deng B, et al. Toxicity of graphene-family nanoparticles: a general review of the origins and mechanisms. Part Fibre Toxicol. 2016 Dec 7;13(1). 
50. Gurunathan S, Kang M-H, Jeyaraj M, Kim J-H. Differential Cytotoxicity of Different Sizes of Graphene Oxide Nanoparticles in Leydig (TM3) and Sertoli (TM4) Cells. Nanomaterials. 2019;9(2):139.

51. Gurcan C, Taheri H, Bianco A, Delogu LG, Yilmazer A. A closer look at the genotoxicity of graphene based materials. J Phys Mater. 2019;3(1):14007.

52. Majeed W, Bourdo S, Petibone DM, Saini V, Vang KB, Nima ZA, et al. The role of surface chemistry in the cytotoxicity profile of graphene: Surface chemistry role in the cytotoxicity profile of graphene. J Appl Toxicol. 2017;37(4):462-70.

53. Li R, Guiney LM, Chang CH, Mansukhani ND, Ji Z, Wang X, et al. Surface Oxidation of Graphene Oxide Determines Membrane Damage, Lipid Peroxidation, and Cytotoxicity in Macrophages in a Pulmonary Toxicity Model. ACS Nano. 2018;12(2):1390-402.

54. Pelin M, Fusco L, León V, Martín C, Criado A, Sosa S, et al. Differential cytotoxic effects of graphene and graphene oxide on skin keratinocytes. Sci Rep . 2017 Dec 7;7(1).

55. Jasim DA, Boutin H, Fairclough M, Ménard-Moyon C, Prenant C, Bianco A, et al. Thickness of functionalized graphene oxide sheets plays critical role in tissue accumulation and urinary excretion: A pilot PET/CT study. Appl Mater Today. 2016;4:2430.

56. Bussy C, Jasim D, Lozano N, Terry D, Kostarelos K. The current graphene safety landscape - a literature mining exercise. Nanoscale. 2015;7(15):6432-5.

57. Wibroe PP, Petersen S V, Bovet N, Laursen BW, Moghimi SM. Soluble and immobilized graphene oxide activates complement system differently dependent on surface oxidation state. Biomaterials. 2016;78:20-6.

58. Oberdörster G, Oberdörster E, Oberdörster J. Nanotoxicology: An Emerging Discipline 
Evolving from Studies of Ultrafine Particles. Environ Health Perspect. 2005;113(7):82339.

59. Tan X, Feng L, Zhang J, Yang K, Zhang S, Liu Z, et al. Functionalization of Graphene Oxide Generates a Unique Interface for Selective Serum Protein Interactions. ACS Appl Mater Interfaces. 2013;5(4):1370-7.

60. Chowdhury SM, Fang J, Sitharaman B. Interaction of graphene nanoribbons with components of the blood vascular system. Futur Sci OA . 2015 Jul 15;1(3).

61. Tu Z, Achazi K, Schulz A, Mülhaupt R, Thierbach S, Rühl E, et al. Combination of Surface Charge and Size Controls the Cellular Uptake of Functionalized Graphene Sheets. Adv Funct Mater. 2017;27(33):1701837.

62. Yue H, Wei W, Yue Z, Wang B, Luo N, Gao Y, et al. The role of the lateral dimension of graphene oxide in the regulation of cellular responses. Biomaterials. 2012;33(16):401321.

63. Ou L, Lin S, Song B, Liu J, Lai R, Shao L. The mechanisms of graphene-based materialsinduced programmed cell death: a review of apoptosis, autophagy, and programmed necrosis. Int J Nanomedicine. 2017; Volume 12:6633-46.

64. Duan G, Zhang Y, Luan B, Weber JK, Zhou RW, Yang Z, et al. Graphene-Induced Pore Formation on Cell Membranes. Sci Rep. 2017;7(1):42767.

65. Schinwald A, Murphy FA, Jones A, MacNee W, Donaldson K. Graphene-Based Nanoplatelets: A New Risk to the Respiratory System as a Consequence of Their Unusual Aerodynamic Properties. ACS Nano. 2012;6(1):736-46.

66. Pettitt ME, Lead JR. Minimum physicochemical characterisation requirements for nanomaterial regulation. Environ Int. 2013;52:41-50. 
67. Rasmussen K, Rauscher H, Mech A, Riego Sintes J, Gilliland D, González M, et al. Physico-chemical properties of manufactured nanomaterials - Characterisation and relevant methods. An outlook based on the OECD Testing Programme. Regul Toxicol Pharmacol. 2018;92:8-28.

68. Gao X, Lowry G V. Progress towards standardized and validated characterizations for measuring physicochemical properties of manufactured nanomaterials relevant to nano health and safety risks. NanoImpact. 2018;9:14-30.

69. Liao K-H, Lin Y-S, Macosko CW, Haynes CL. Cytotoxicity of Graphene Oxide and Graphene in Human Erythrocytes and Skin Fibroblasts. ACS Appl Mater Interfaces. 2011;3(7):2607-15.

70. Bussy C, Kostarelos K. Culture Media Critically Influence Graphene Oxide Effects on Plasma Membranes. Chem. 2017;2(3):322-3.

71. Peterangelo SC, Seybold PG. Synergistic interactions among QSAR descriptors. Int J Quantum Chem. 2004;96(1):1-9.

72. Rácz A, Bajusz D, Héberger K. Intercorrelation Limits in Molecular Descriptor Preselection for QSAR/QSPR. Mol Inform. 2019;38(8-9):1800154.

73. Taylor K. Experiences of the REACH testing proposals system to reduce animal testing. ALTEX . 2014 Jul 8;

74. Fragki S, Piersma AH, Rorije E, Zeilmaker MJ. In vitro to in vivo extrapolation of effective dosimetry in developmental toxicity testing: Application of a generic PBK modelling approach. Toxicol Appl Pharmacol. 2017;332:109-20.

75. Teeguarden JG, Hinderliter PM, Orr G, Thrall BD, Pounds JG. Particokinetics In Vitro: Dosimetry Considerations for In Vitro Nanoparticle Toxicity Assessments. Toxicol Sci. 
2007;95(2):300-12.

76. Pelin M, Sosa S, Prato M, Tubaro A. Occupational exposure to graphene based nanomaterials: risk assessment. Nanoscale. 2018;10(34):15894-903.

77. Akhavan O, Ghaderi E, Akhavan A. Size-dependent genotoxicity of graphene nanoplatelets in human stem cells. Biomaterials. 2012;33(32):8017-25.

78. Mittal S, Kumar V, Dhiman N, Chauhan LKS, Pasricha R, Pandey AK. Physico-chemical properties based differential toxicity of graphene oxide/reduced graphene oxide in human lung cells mediated through oxidative stress. Sci Rep. 2016 Jan 17;6(1).

79. Gies V, Zou S. Systematic toxicity investigation of graphene oxide: evaluation of assay selection, cell type, exposure period and flake size. Toxicol Res (Camb). 2018;7(1):93101.

80. Sauvain J-J, Rossi MJ, Riediker M. Comparison of Three Acellular Tests for Assessing the Oxidation Potential of Nanomaterials. Aerosol Sci Technol. 2013;47(2):218-27.

81. Sayre PG, Steinhäuser KG, van Teunenbroek T. Methods and data for regulatory risk assessment of nanomaterials: Questions for an expert consultation. NanoImpact. 2017;8:20-7.

82. Drasler B, Sayre P, Steinhäuser KG, Petri-Fink A, Rothen-Rutishauser B. In vitro approaches to assess the hazard of nanomaterials. NanoImpact. 2017;8:99-116.

83. Fusco L, Garrido M, Martín C, Sosa S, Ponti C, Centeno A, et al. Skin irritation potential of graphene-based materials using a non-animal test. Nanoscale. 2020;12(2):610-22.

84. Hill CE, Myers JP, Vandenberg LN. Nonmonotonic Dose-Response Curves Occur in Dose Ranges That Are Relevant to Regulatory Decision-Making. Dose-Response. 2018;16(3):155932581879828. 
85. SP M, N L, M K, AE DR-C, L N, E V, et al. Detection of Endotoxin Contamination of Graphene Based Materials Using the TNF- $\alpha$ Expression Test and Guidelines for Endotoxin-Free Graphene Oxide Production. PLoS One. 2016 Nov 1;11(11).

86. Kauling AP, Seefeldt AT, Pisoni DP, Pradeep RC, Bentini R, Oliveira RVB, et al. The Worldwide Graphene Flake Production. Adv Mater. 2018 Nov 1;30(44):1803784. 


\section{Supplementary Information}

\section{Figure S1: Attribution of toxicity score.}

The first step is to extract the data in the articles.

We gather the available information on physicochemical characterization as well as the information on toxicity assays, as shown in the table below:

We then consider the exposure dose that lead to a significant response, compared to the negative control (cells in cell culture media). The first dose leading to a significant response will be used to attribute a toxicity score to a GBM ranging from 0 to 5 . The toxicity score will be then used to classify the GBM as highly, moderately or no/poorly toxic as shown in the following table:

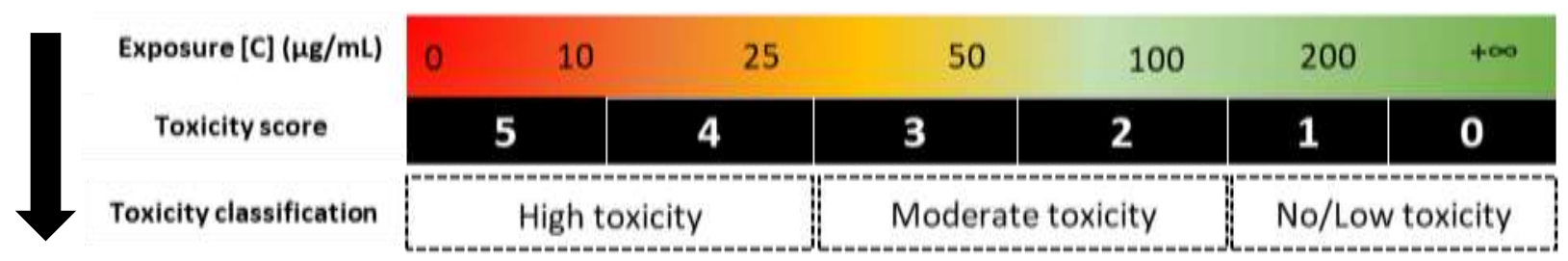

\section{Example:}

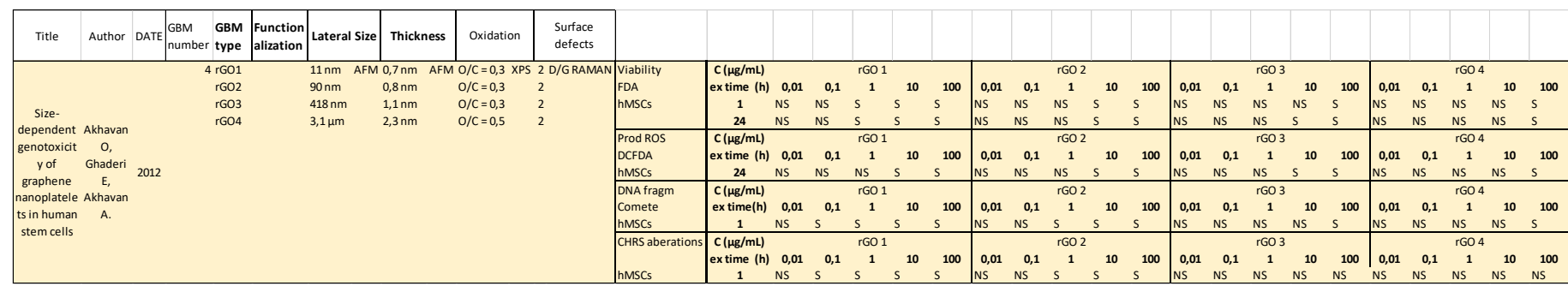

Figure S1 - Attribution of toxicity score.

In this example, we extracted the data from a paper describing 4 rGO.

For rGO1: For viability measured by FDA incorporation, 1 hour or 24 hours of exposure of hMSCc cells to rGO1 caused a significant decrease of viability from a concentration of $1 \mu \mathrm{g} / \mathrm{mL}$. Hence, for the endpoint of cytotoxicity measured after a short ( $\leq 12$ hours) and a medium (24 hours) exposure time, rGO1 will be attributed a score of $\mathbf{5}$, and classified as highly toxic. rG01 causes indeed a toxic response even at a very low dose.

For $r$ GO4: When exposed to rGO4, hMSCc cells show a decrease of viability at the concentration of $100 \mu \mathrm{g} / \mathrm{mL}$ (for both short and medium exposure time). rGO4 toxicity score is then $\mathbf{2}$, and will be classified as moderately toxic: only a quite important dose will cause a toxic response. The 
score is time specific and endpoint specific. In this example, rGO1, rGO2, rGO3 and rGO4 will be given a score (leading to a toxicity classification) for:

\section{- Cytotoxicity}

- Measured at short exposure time ( $\leq 12$ hours)

- Measured at medium exposure time (24 hours)

- Oxidative stress

- Measured at medium exposure time (24 hours)

- Genotoxicity

$\circ \quad$ Measured at medium exposure time (24 hours) 
Figure S2: 2D graphs that do not highlight an obvious structure-activity relationshipPlease note that for these graphs, the color has no signification

\section{A. Lateral size and cytotoxicity}
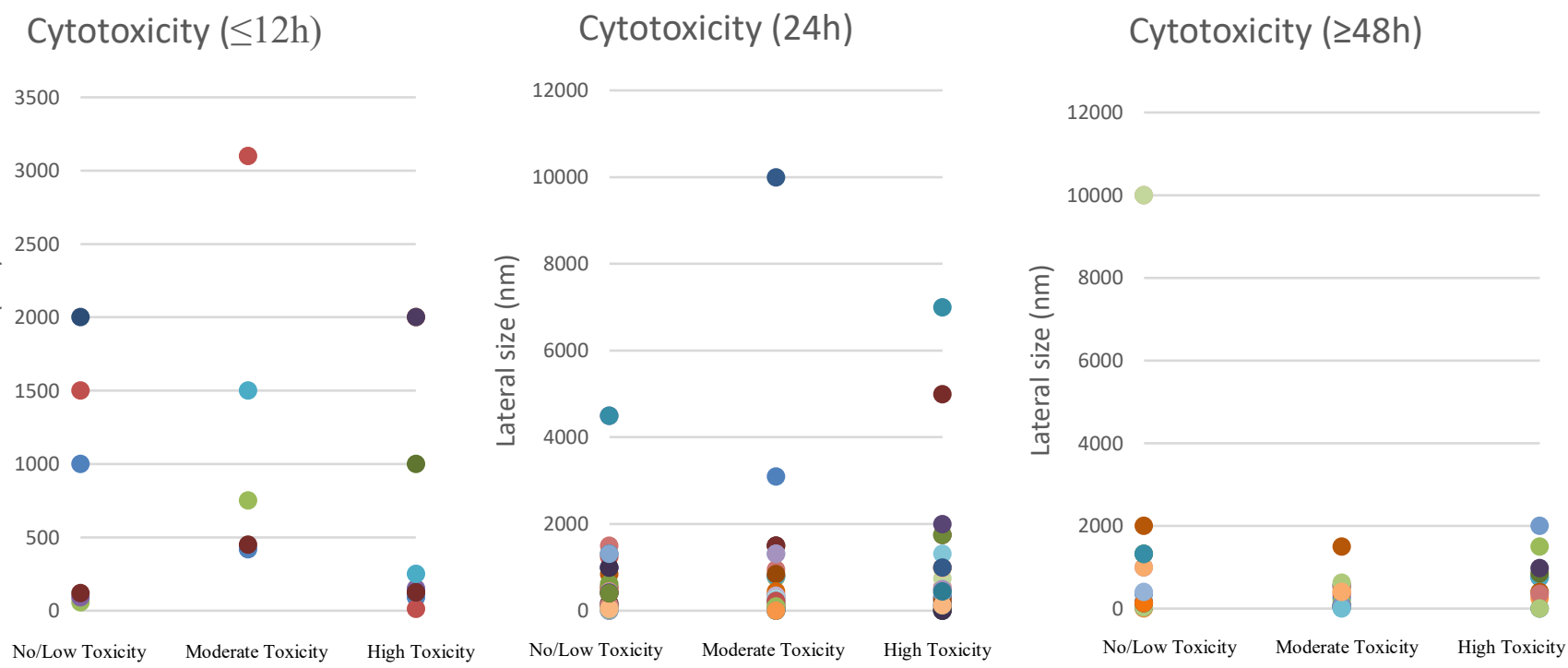

Figure S2-A: Lateral Size and Cytotoxicity

\section{B. Median size and cytotoxicity}
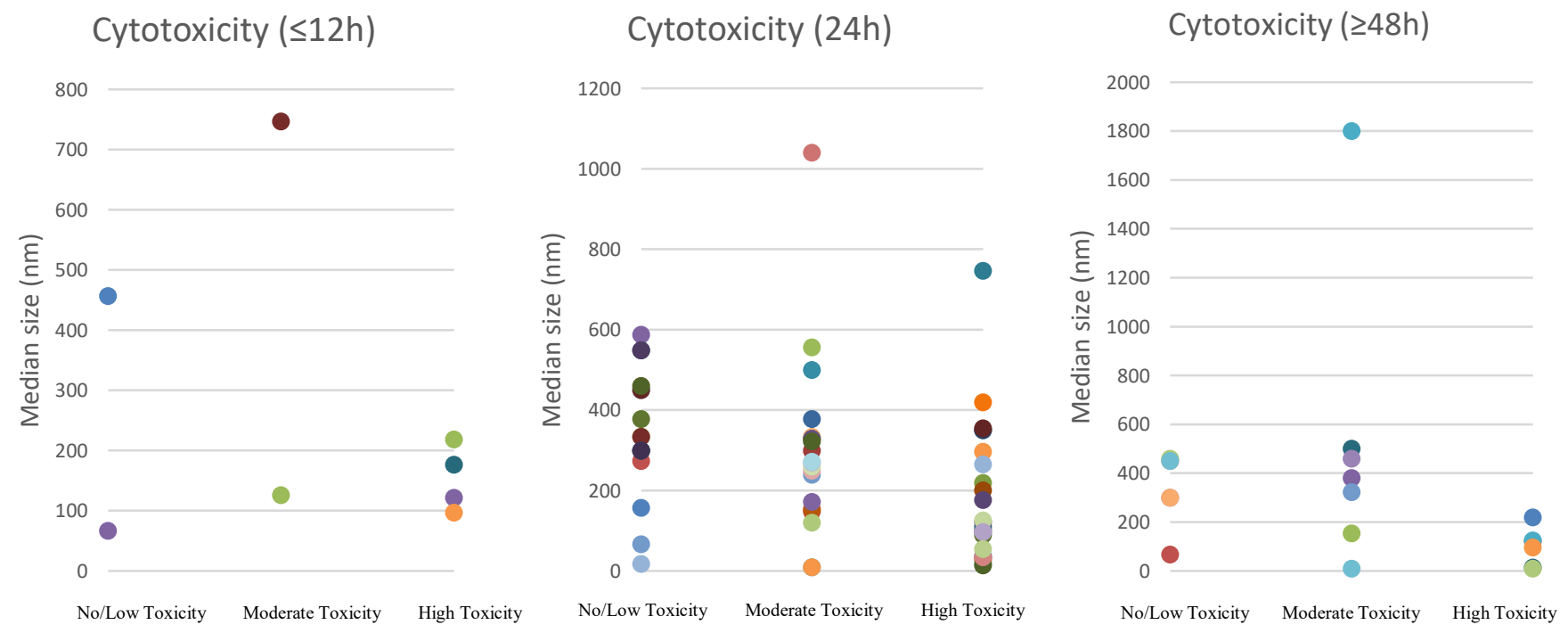

Figure S2-B: Median Size and Cytotoxicity 


\section{Thickness and cytotoxicity}

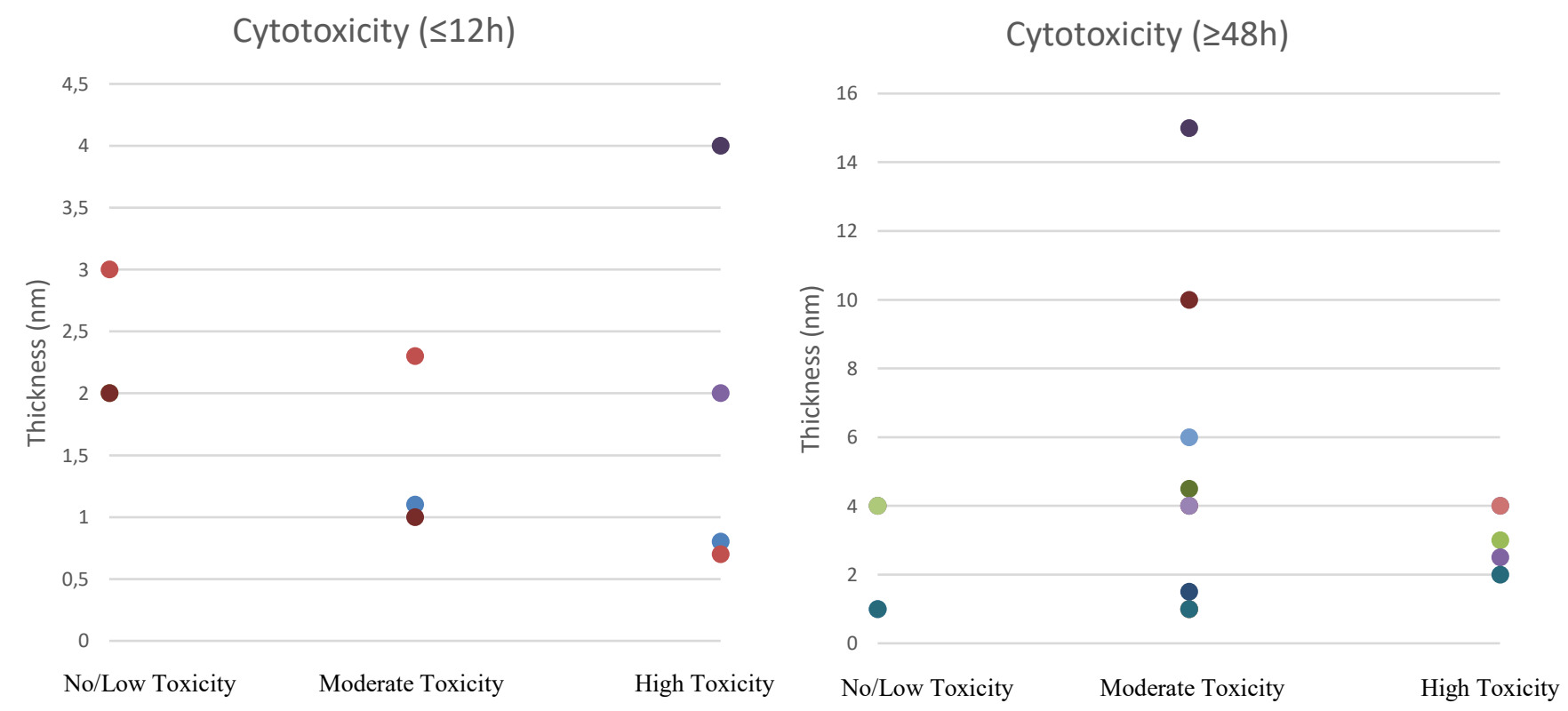

Figure S2-C: Thickness and Cytotoxicity

\section{Oxidation state and cytotoxicity}

Cytotoxicity (24h)

60

50

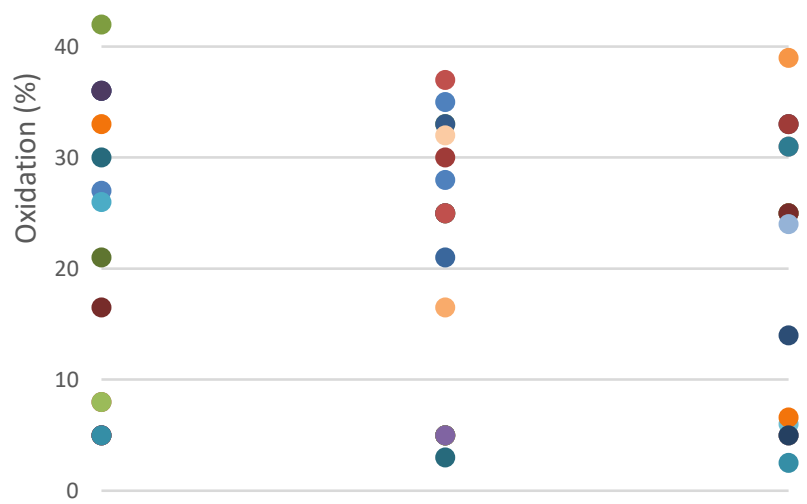

No/Low Toxicity

Moderate Toxicity

High Toxicity

Cytotoxicity ( $\geq 48 \mathrm{~h})$

60
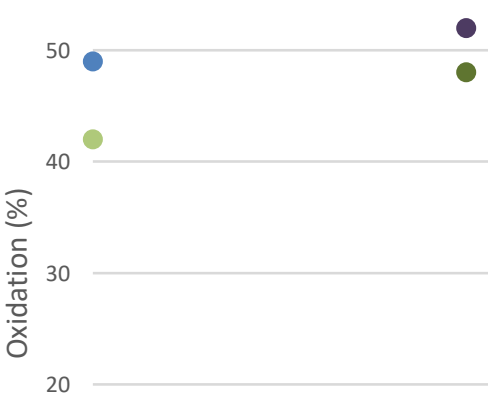

10

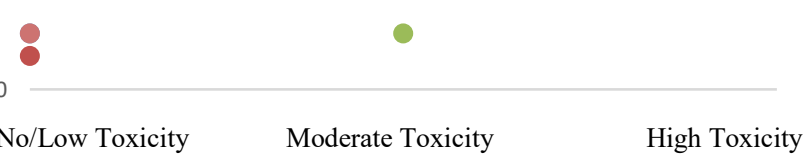

Figure S2-D: Oxidation state and cytotoxicity 


\section{E. Oxidative stress and lateral size}

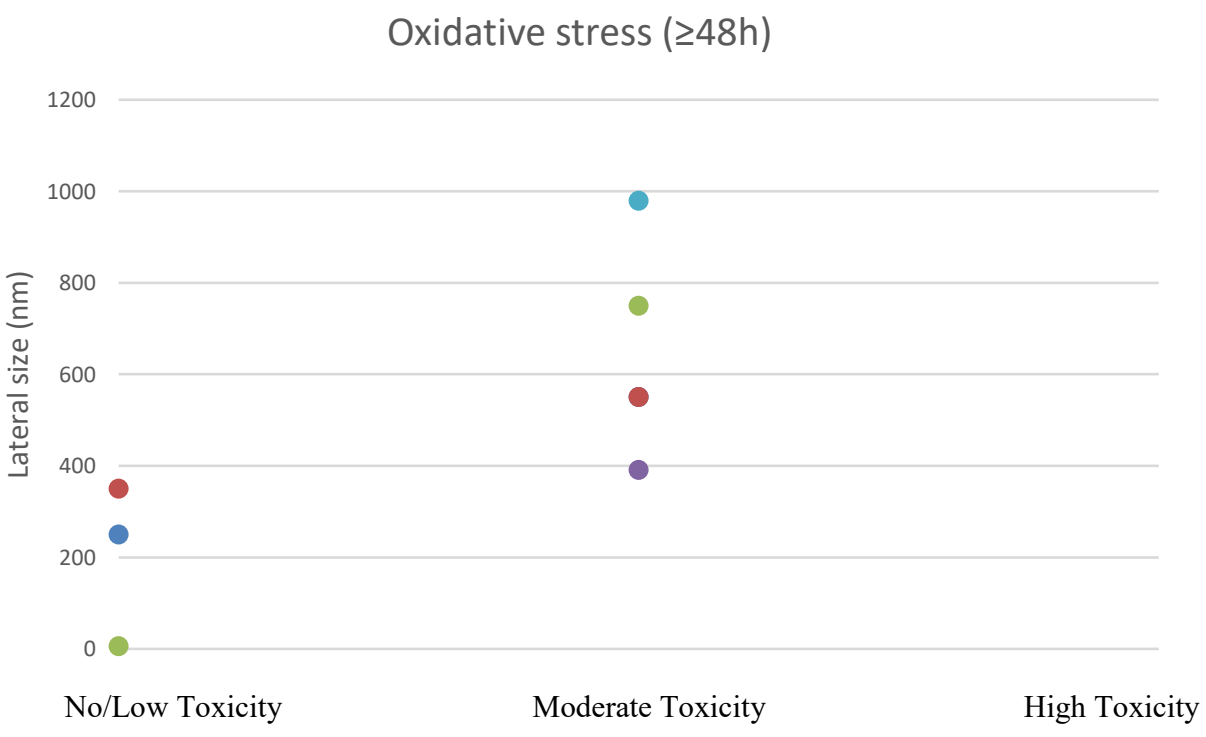

Figure S2-E: Lateral size and oxidative stress

\section{F. Oxidative stress and median size}

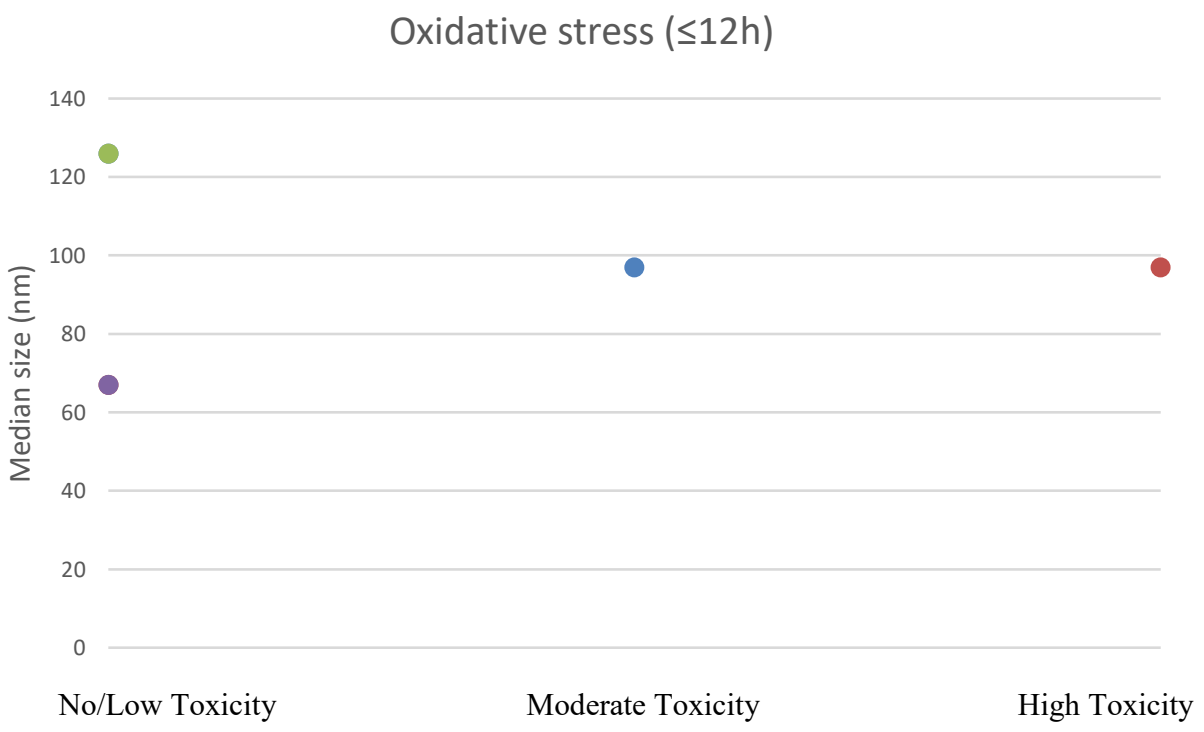

Figure S2-F: Median size and oxidative stress 


\section{G. Oxidative stress and thickness}

Oxidative stress (24h)

25

20
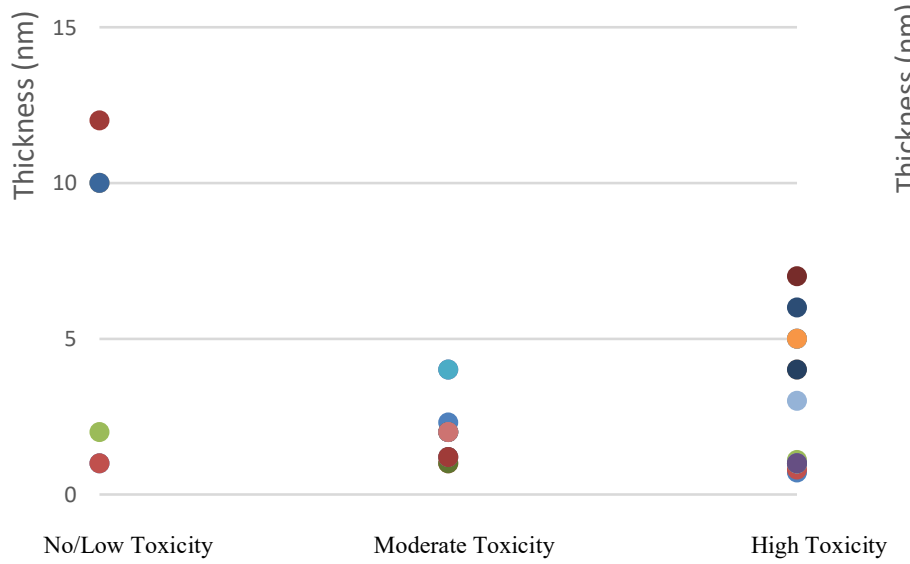

Oxidative stress ( $\geq 48 \mathrm{~h}$ )

4,5

3,5

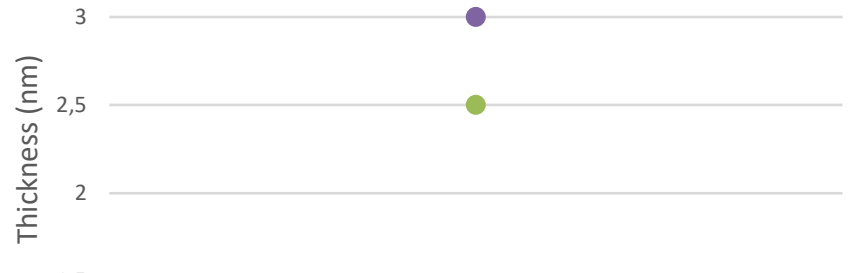

1,5

1

0,5

0

No/Low Toxicity

Moderate Toxicity

High Toxicity

Figure S2-G: Thickness and oxidative stress

H. Oxidative stress and oxidation state 
Oxidative stress $24 \mathrm{~h}$

60

50

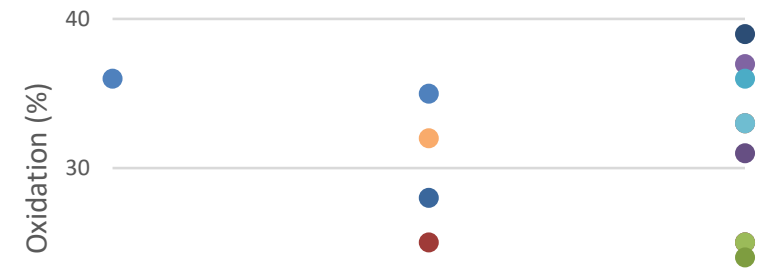

20

10

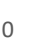

No/Low Toxicity

Moderate Toxicity

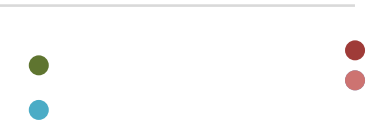

High Toxicity
Oxidative stress $(\leq 12 \mathrm{~h})$

40

35

30

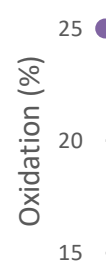

10

5

0

No/Low Toxicity Moderate Toxicity High Toxicity

Figure S2-H: Oxidation state and oxidative stress

I. Oxidative stress and surface defects (ID/IG)

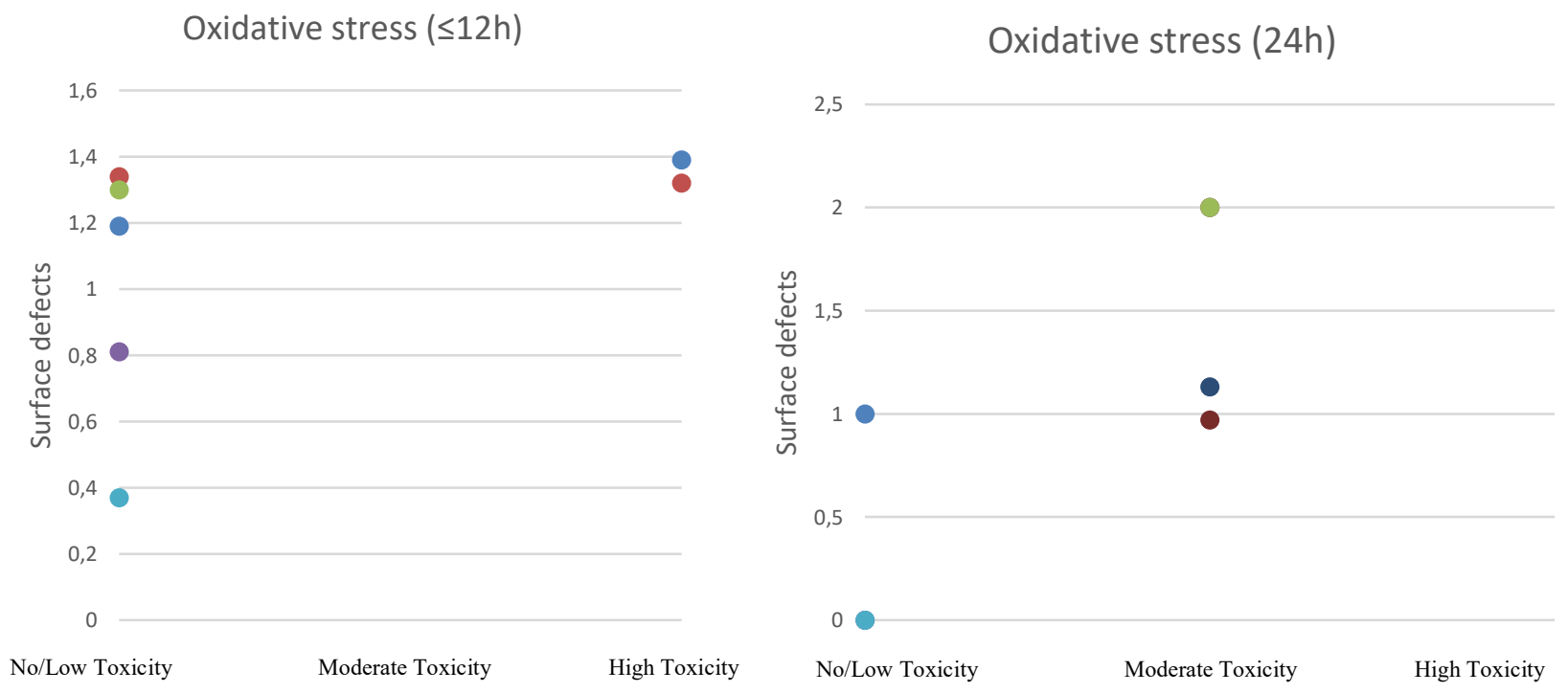

Figure S2-I: Surface defects and oxidative stress 
Figure S3: Assays used for major endpoints in in vitro studies

S3-A Cell viability / Mortality assessment

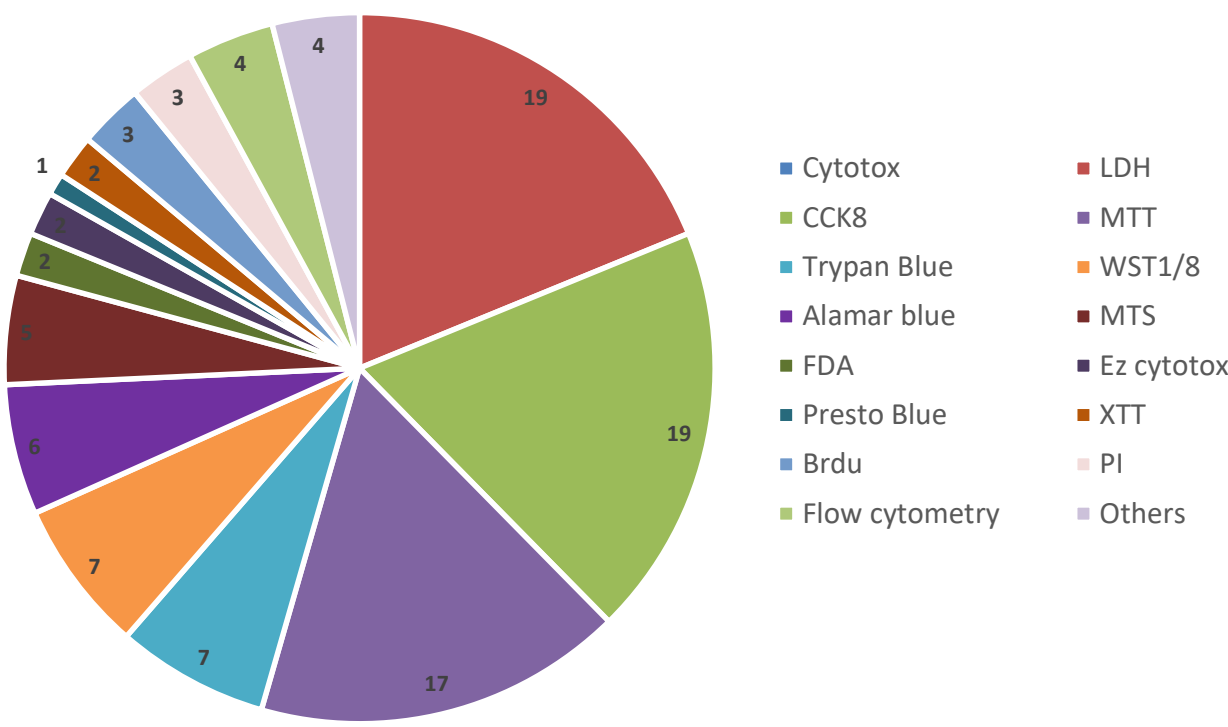

S3-B Oxidative Stress Assessment

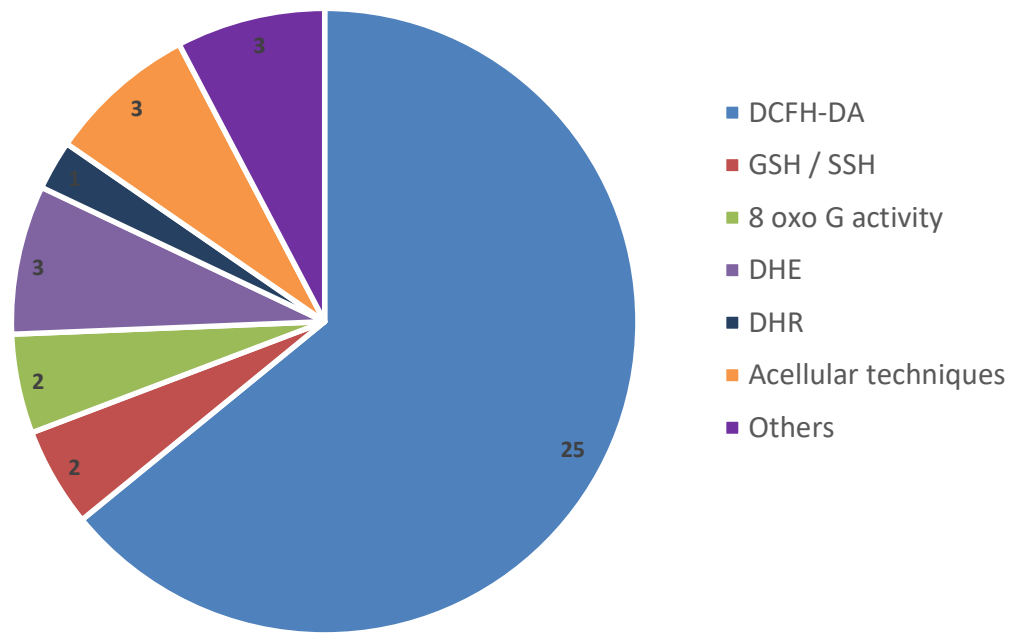


S3-C Inflammation assessment

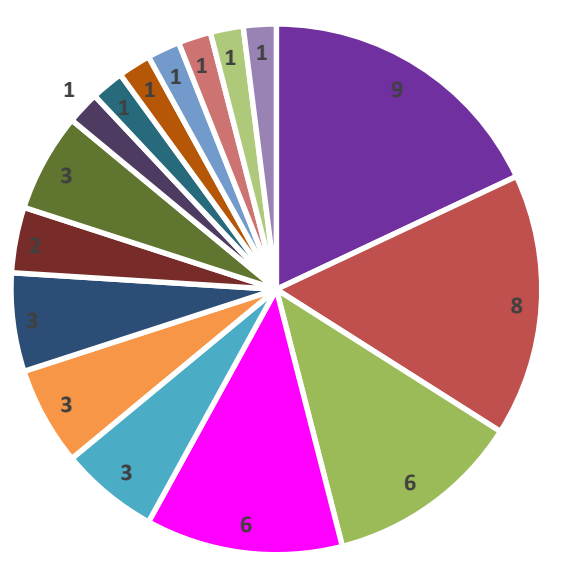

- IL-6

- TNF-a

- IL-10

- IL-1b

- IL-1a

- IL-8

- GM-CSF

- PF4

- MCP

- IL-12

- TFN-g

- TGF-b

- Smad

- IFN-f

- Histamine

- IL-2

S3-D Genotoxicity assessment

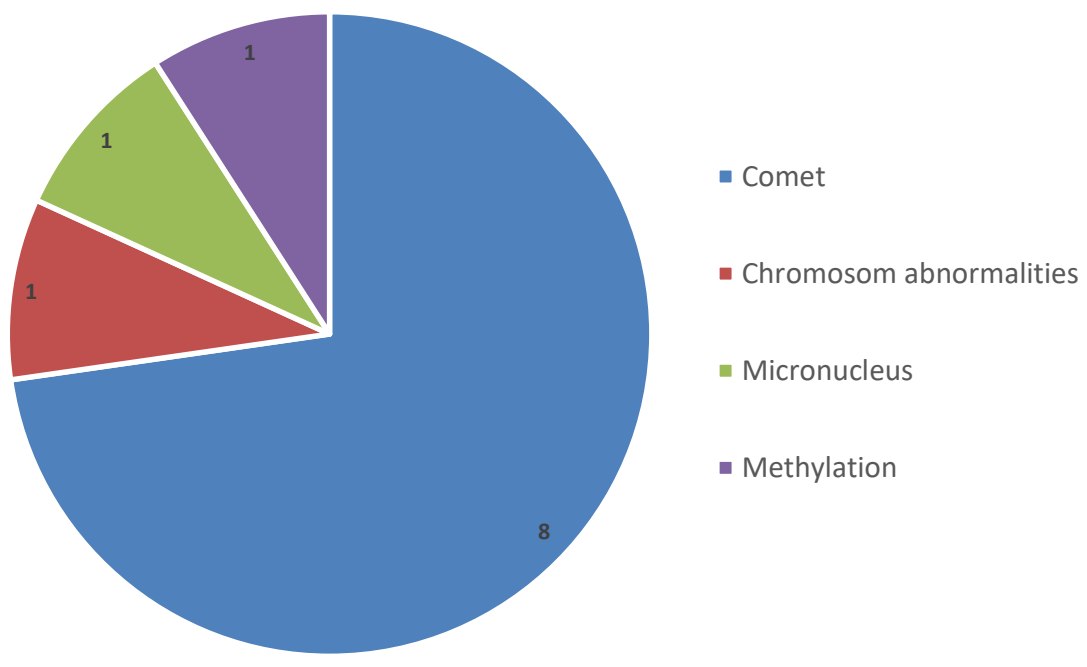




\section{List S4: Publications included in our database}

1. Akhavan O, Ghaderi E, Akhavan A. Size-dependent genotoxicity of graphene nanoplatelets in human stem cells. Biomaterials. 2012;33(32):8017-8025. doi:10.1016/j.biomaterials.2012.07.040

2. Arbo MD, Altknecht LF, Cattani S, et al. In vitro cardiotoxicity evaluation of graphene oxide. Mutat Res - Genet Toxicol Environ Mutagen. 2019;841:8-13. doi:10.1016/j.mrgentox.2019.03.004

3. Babadaei MMN, Moghaddam MF, Solhvand S, et al. Biophysical, bioinformatical, cellular, and molecular investigations on the effects of graphene oxide nanosheets on the hemoglobin structure and lymphocyte cell cytotoxicity. Int $J$ Nanomedicine. 2018;13:6871-6884. doi:10.2147/IJN.S174048

4. Bengtson S, Kling K, Madsen AM, et al. No cytotoxicity or genotoxicity of graphene and graphene oxide in murine lung epithelial FE1 cells in vitro. Environ Mol Mutagen. 2016;57(6):469-482. doi:10.1002/em.22017

5. Chang Y, Yang ST, Liu JH, et al. In vitro toxicity evaluation of graphene oxide on A549 cells. Toxicol Lett. 2011;200(3):201-210. doi:10.1016/j.toxlet.2010.11.016

6. Chatterjee N, Yang JS, Choi J. Differential genotoxic and epigenotoxic effects of graphene family nanomaterials (GFNs) in human bronchial epithelial cells. Mutat Res - Genet Toxicol Environ Mutagen. 2016;798-799:1-10. doi:10.1016/j.mrgentox.2016.01.006

7. Chatterjee N, Eom H-J, Choi J. A systems toxicology approach to the surface functionality control of graphene-cell interactions. Biomaterials. 2014;35(4):1109-1127. doi:10.1016/j.biomaterials.2013.09.108

8. Chatterjee N, Yang JS, Park K, Oh SM, Park J, Choi J. Screening of toxic potential of graphene family nanomaterials using in vitro and alternative in vivo toxicity testing systems. Environ Health Toxicol. 2015;30:e2015007. doi:10.5620/eht.e2015007

9. Khim Chng EL, Chua CK, Pumera M. Graphene oxide nanoribbons exhibit significantly greater toxicity than graphene oxide nanoplatelets. Nanoscale. 2014;6(18):10792-10797. doi:10.1039/c4nr03608e

10. Chong $\mathrm{Y}$, Ma $\mathrm{Y}$, Shen $\mathrm{H}$, et al. The in vitro and in vivo toxicity of graphene quantum dots. Biomaterials. 2014;35(19):5041-5048. doi:10.1016/j.biomaterials.2014.03.021

11. Chowdhury SM, Fang J, Sitharaman B. Interaction of graphene nanoribbons with components of the blood vascular system. Futur Sci OA. 2015;1(3). doi:10.4155/fso.15.17

12. Chowdhury SM, Kanakia S, Toussaint JD, et al. In vitro hematological and in vivo vasoactivity assessment of dextran functionalized graphene. Sci Rep. 2013;3(1):1-10. doi: $10.1038 /$ srep02584

13. Cibecchini G, Veronesi M, Catelani T, Bandiera T, Guarnieri D, Pompa PP. Antiangiogenic Effect of Graphene Oxide in Primary Human Endothelial Cells. ACS Appl 
Mater Interfaces. 2020;12(20):22507-22518. doi:10.1021/acsami.0c03404

14. De Marzi L, Ottaviano L, Perrozzi F, et al. Flake size-dependent cyto and genotoxic evaluation of graphene oxide on in vitro $\mathrm{A} 549, \mathrm{CaCo} 2$ and vero cell lines. $J$ Biol Regul Homeost Agents. 2014;28(2):281-289.

15. Saha D, Heldt CL, Gencoglu MF, Vijayaragavan KS, Chen J, Saksule A. A study on the cytotoxicity of carbon-based materials. Mater Sci Eng C. 2016;68(C):101-108. doi:10.1016/j.msec.2016.05.094

16. Du L, Wu S, Li Y, Zhao X, Ju X, Wang Y. Cytotoxicity of PEGylated graphene oxide on lymphoma cells. In: Bio-Medical Materials and Engineering. Vol 24. IOS Press; 2014:2135-2141. doi:10.3233/BME-141024

17. Farahani M, Rezaei-Tavirani M, Zali H, Hatamie S, Ghasemi N. Systems toxicology assessment revealed the impact of graphene-based materials on cell cycle regulators. $J$ Biomed Mater Res Part A. 2020;108(7):1520-1533. doi:10.1002/jbm.a.36923

18. Frontiñán-Rubio J, Victoria Gómez M, Martín C, González-Domínguez JM, Durán-Prado M, Vázquez E. Differential effects of graphene materials on the metabolism and function of human skin cells. Nanoscale. 2018;10(24):11604-11615. doi:10.1039/c8nr00897c

19. Gies V, Zou S. Systematic toxicity investigation of graphene oxide: evaluation of assay selection, cell type, exposure period and flake size. Toxicol Res (Camb). 2018;7(1):93101. doi:10.1039/C7TX00278E

20. Guarnieri D, Sánchez-Moreno P, Del Rio Castillo AE, et al. Biotransformation and Biological Interaction of Graphene and Graphene Oxide during Simulated Oral Ingestion. Small. 2018;14(24). doi:10.1002/smll.201800227

21. Gurunathan S, Iqbal MA, Qasim M, et al. Evaluation of Graphene Oxide Induced Cellular Toxicity and Transcriptome Analysis in Human Embryonic Kidney Cells. Published online 2019. doi:10.3390/nano9070969

22. Gurunathan S, Kang MH, Jeyaraj M, Kim JH. Differential immunomodulatory effect of graphene oxide and vanillin-functionalized graphene oxide nanoparticles in human acute monocytic leukemia cell line (THP-1). Int $J$ Mol Sci. 2019;20(2). doi:10.3390/ijms20020247

23. Gurunathan S, Kang M-H, Jeyaraj M, Kim J-H. Differential Cytotoxicity of Different Sizes of Graphene Oxide Nanoparticles in Leydig (TM3) and Sertoli (TM4) Cells. Nanomaterials. 2019;9(2):139. doi:10.3390/nano9020139

24. Pastrana HF, Cartagena-Rivera AX, Raman A, Ávila A. Evaluation of the elastic Young's modulus and cytotoxicity variations in fibroblasts exposed to carbon-based nanomaterials. J Nanobiotechnology. 2019;17(1):32. doi:10.1186/s12951-019-0460-8

25. Jaworski S, Sawosz E, Grodzik M, et al. In vitro evaluation of the effects of graphene platelets on glioblastoma multiforme cells. Int J Nanomedicine. 2013;8:413-420. doi:10.2147/IJN.S39456 
26. Jaworski S, Strojny B, Sawosz E, et al. Degradation of mitochondria and oxidative stress as the main mechanism of toxicity of pristine graphene on U87 glioblastoma cells and tumors and HS-5 cells. Int J Mol Sci. 2019;20(3). doi:10.3390/ijms20030650

27. Jia P-P, Sun T, Junaid M, et al. Nanotoxicity of different sizes of graphene (G) and graphene oxide (GO) in vitro and in vivo. Environ Pollut. 2019;247:595-606. doi:10.1016/j.envpol.2019.01.072

28. Jin C, Wang F, Tang Y, Zhang X, Wang J, Yang Y. Distribution of graphene oxide and TiO2-graphene oxide composite in A549 cells. Biol Trace Elem Res. 2014;159(1-3):393398. doi:10.1007/s12011-014-0027-3

29. Ma J, Liu R, Wang X, et al. Crucial Role of Lateral Size for Graphene Oxide in Activating Macrophages and Stimulating Pro-inflammatory Responses in Cells and Animals. ACS Nano. 2015;9(10):10498-10515. doi:10.1021/acsnano.5b04751

30. Kang Y, Liu J, Wu J, et al. Graphene oxide and reduced graphene oxide induced neural pheochromocytoma-derived PC12 cell lines apoptosis and cell cycle alterations via the ERK signaling pathways. Int $J$ Nanomedicine. 2017;12:5511-5523. doi:10.2147/IJN.S141032

31. Kucki M, Rupper P, Sarrieu C, et al. Interaction of graphene-related materials with human intestinal cells: An in vitro approach. Nanoscale. 2016;8(16):8749-8760. doi:10.1039/c6nr00319b

32. Lahiani MH, Gokulan K, Williams K, Khodakovskaya M V., Khare S. Graphene and carbon nanotubes activate different cell surface receptors on macrophages before and after deactivation of endotoxins. J Appl Toxicol. 2017;37(11):1305-1316. doi:10.1002/jat.3477

33. Lammel T, Boisseaux P, Fernández-Cruz ML, Navas JM. Internalization and cytotoxicity of graphene oxide and carboxyl graphene nanoplatelets in the human hepatocellular carcinoma cell line Hep G2. Part Fibre Toxicol. 2013;10(1). doi:10.1186/1743-8977-1027

34. Lebre F, Boland JB, Gouveia P, et al. Pristine graphene induces innate immune training. Nanoscale. 2020;12(20):11192-11200. doi:10.1039/c9nr09661b

35. Li J, Zhang X, Jiang J, et al. Systematic assessment of the toxicity and potential mechanism of graphene derivatives in vitro and in vivo. Toxicol Sci. 2019;167(1):190-201. doi:10.1093/toxsci/kfy235

36. Li R, Guiney LM, Chang CH, et al. Surface Oxidation of Graphene Oxide Determines Membrane Damage, Lipid Peroxidation, and Cytotoxicity in Macrophages in a Pulmonary Toxicity Model. ACS Nano. 2018;12(2):1390-1402. doi:10.1021/acsnano.7b07737

37. Li Y, Feng L, Shi X, et al. Surface coating-dependent cytotoxicity and degradation of graphene derivatives: Towards the design of non-toxic, degradable nano-graphene. Small. 2014;10(8):1544-1554. doi:10.1002/smll.201303234

38. Li Y, Liu Y, Fu Y, et al. The triggering of apoptosis in macrophages by pristine graphene 
through the MAPK and TGF-beta signaling pathways. Biomaterials. 2012;33(2):402-411. doi:10.1016/j.biomaterials.2011.09.091

39. Liao Y, Wang W, Huang X, Sun Y, Tian S, Cai P. Reduced graphene oxide triggered epithelial-mesenchymal transition in A549 cells. Sci Rep. 2018;8(1):1-12. doi:10.1038/s41598-018-33414-x

40. Lv M, Zhang Y, Liang L, et al. Effect of graphene oxide on undifferentiated and retinoic acid-differentiated SH-SY5Y cells line. Nanoscale. 2012;4(13):3861-3866. doi: $10.1039 / \mathrm{c} 2 \mathrm{nr} 30407 \mathrm{~d}$

41. Majeed W, Bourdo S, Petibone DM, et al. The role of surface chemistry in the cytotoxicity profile of graphene: Surface chemistry role in the cytotoxicity profile of graphene. $J$ Appl Toxicol. 2017;37(4):462-470. doi:10.1002/jat.3379

42. Malanagahalli S, Murera D, Martín C, et al. Few layer graphene does not affect cellular homeostasis of mouse macrophages. Nanomaterials. 2020;10(2). doi:10.3390/nano10020228

43. Markovic ZM, Harhaji-Trajkovic LM, Todorovic-Markovic BM, et al. In vitro comparison of the photothermal anticancer activity of graphene nanoparticles and carbon nanotubes. Biomaterials. 2011;32(4):1121-1129. doi:10.1016/j.biomaterials.2010.10.030

44. Markovic ZM, Ristic BZ, Arsikin KM, et al. Graphene quantum dots as autophagyinducing photodynamic agents. Biomaterials. 2012;33(29):7084-7092. doi:10.1016/j.biomaterials.2012.06.060

45. Matesanz MC, Vila M, Feito MJ, et al. The effects of graphene oxide nanosheets localized on F-actin filaments on cell-cycle alterations. Biomaterials. 2013;34(5):1562-1569. doi:10.1016/j.biomaterials.2012.11.001

46. Mittal S, Kumar V, Dhiman N, Chauhan LKS, Pasricha R, Pandey AK. Physico-chemical properties based differential toxicity of graphene oxide/reduced graphene oxide in human lung cells mediated through oxidative stress. Sci Rep. 2016;6(1). doi:10.1038/srep39548

47. Mukherjee SP, Kostarelos K, Fadeel B. Cytokine Profiling of Primary Human Macrophages Exposed to Endotoxin-Free Graphene Oxide: Size-Independent NLRP3 Inflammasome Activation. Adv Healthc Mater. 2018;7(4). doi:10.1002/adhm.201700815

48. Mullick Chowdhury S, Lalwani G, Zhang K, Yang JY, Neville K, Sitharaman B. Cell specific cytotoxicity and uptake of graphene nanoribbons. Biomaterials. 2013;34(1):283293. doi:10.1016/j.biomaterials.2012.09.057

49. Nasirzadeh N, Azari MR, Rasoulzadeh Y, Mohammadian Y. An assessment of the cytotoxic effects of graphene nanoparticles on the epithelial cells of the human lung. Toxicol Ind Health. 2019;35(1):79-87. doi:10.1177/0748233718817180

50. Nurunnabi M, Khatun Z, Huh KM, et al. In vivo biodistribution and toxicology of carboxylated graphene quantum dots. ACS Nano. 2013;7(8):6858-6867. doi:10.1021/nn402043c 
51. Pang L, Dai C, Bi L, Guo Z, Fan J. Biosafety and Antibacterial Ability of Graphene and Graphene Oxide In Vitro and In Vivo. Nanoscale Res Lett. 2017;12. doi:10.1186/s11671017-2317-0

52. Park EJ, Lee GH, Han BS, et al. Toxic response of graphene nanoplatelets in vivo and in vitro. Arch Toxicol. 2015;89(9):1557-1568. doi:10.1007/s00204-014-1303-x

53. Pelin M, Fusco L, Martín C, et al. Graphene and graphene oxide induce ROS production in human HaCaT skin keratinocytes: The role of xanthine oxidase and NADH dehydrogenase. Nanoscale. 2018;10(25):11820-11830. doi:10.1039/c8nr02933d

54. Pelin M, Fusco L, León V, et al. Differential cytotoxic effects of graphene and graphene oxide on skin keratinocytes. Sci Rep. 2017;7(1). doi:10.1038/srep40572

55. Russier J, Treossi E, Scarsi A, et al. Evidencing the mask effect of graphene oxide: A comparative study on primary human and murine phagocytic cells. Nanoscale. 2013;5(22):11234-11247. doi:10.1039/c3nr03543c

56. Sasidharan A, Swaroop S, Chandran P, Nair S, Koyakutty M. Cellular and molecular mechanistic insight into the DNA-damaging potential of few-layer graphene in human primary endothelial cells. Nanomedicine Nanotechnology, Biol Med. 2016;12(5):13471355. doi:10.1016/j.nano.2016.01.014

57. Schirinzi GF, Pérez-Pomeda I, Sanchís J, Rossini C, Farré M, Barceló D. Cytotoxic effects of commonly used nanomaterials and microplastics on cerebral and epithelial human cells. Environ Res. 2017;159:579-587. doi:10.1016/j.envres.2017.08.043

58. Serrano MC, Feito MJ, González-Mayorga A, Diez-Orejas R, Matesanz MC, Portolés MT. Response of macrophages and neural cells in contact with reduced graphene oxide microfibers. Biomater Sci. 2018;6(11):2987-2997. doi:10.1039/c8bm00902c

59. Singh SK, Singh MK, Kulkarni PP, Sonkar VK, Grácio JJA, Dash D. Amine-modified graphene: Thrombo-protective safer alternative to graphene oxide for biomedical applications. ACS Nano. 2012;6(3):2731-2740. doi:10.1021/nn300172t

60. Tabish TA, Scotton CJ, J Ferguson DC, et al. Biocompatibility and toxicity of graphene quantum dots for potential application in photodynamic therapy. Nanomedicine. 2018;13(15):1923-1937. doi:10.2217/nnm-2018-0018

61. Talukdar Y, Rashkow JT, Lalwani G, Kanakia S, Sitharaman B. The effects of graphene nanostructures on mesenchymal stem cells. Biomaterials. 2014;35(18):4863-4877. doi:10.1016/j.biomaterials.2014.02.054

62. Tang Z, Zhao L, Yang Z, et al. Mechanisms of oxidative stress, apoptosis, and autophagy involved in graphene oxide nanomaterial anti-osteosarcoma effect. Int J Nanomedicine. 2018;13:2907-2919. doi:10.2147/IJN.S159388

63. Tian X, Xiao BB, Wu A, et al. Hydroxylated-graphene quantum dots induce cells senescence in both p53-dependent and -independent manner. Toxicol Res (Camb). 2016;5(6):1639-1648. doi:10.1039/c6tx00209a 
64. Vranic S, Rodrigues AF, Buggio M, et al. Live Imaging of Label-Free Graphene Oxide Reveals Critical Factors Causing Oxidative-Stress-Mediated Cellular Responses. ACS Nano. 2018;12(2):1373-1389. doi:10.1021/acsnano.7b07734

65. Wan B, Wang ZX, Lv QY, et al. Single-walled carbon nanotubes and graphene oxides induce autophagosome accumulation and lysosome impairment in primarily cultured murine peritoneal macrophages. Toxicol Lett. 2013;221(2):118-127. doi:10.1016/j.toxlet.2013.06.208

66. Wang D, Zhu L, Chen JF, Dai L. Can graphene quantum dots cause DNA damage in cells? Nanoscale. 2015;7(21):9894-9901. doi:10.1039/c5nr01734c

67. Wang M, Sun Y, Cao X, et al. Graphene quantum dots against human IAPP aggregation and toxicity: In vivo. Nanoscale. 2018;10(42):19995-20006. doi:10.1039/c8nr07180b

68. Wierzbicki M, Sawosz E, Strojny B, Jaworski S, Grodzik M, Chwalibog A. NF-kB-related decrease of glioma angiogenic potential by graphite nanoparticles and graphene oxide nanoplatelets. Sci Rep. 2018;8(1):14733. doi:10.1038/s41598-018-33179-3

69. Wu C, Wang C, Han T, Zhou X, Guo S, Zhang J. Insight into the Cellular Internalization and Cytotoxicity of Graphene Quantum Dots. Adv Healthc Mater. 2013;2(12):1613-1619. doi:10.1002/adhm.201300066

70. $\mathrm{Wu} \mathrm{W}$, Yan $\mathrm{L}, \mathrm{Wu} \mathrm{Q}$, et al. Evaluation of the toxicity of graphene oxide exposure to the eye. Nanotoxicology. 2016;10(9):1329-1340. doi:10.1080/17435390.2016.1210692

71. Feng X, Chen L, Guo W, et al. Graphene oxide induces p62/SQSTM-dependent apoptosis through the impairment of autophagic flux and lysosomal dysfunction in PC12 cells. Acta Biomater. 2018;81:278-292. doi:10.1016/j.actbio.2018.09.057

72. Xu L, Dai Y, Wang Z, et al. Graphene quantum dots in alveolar macrophage: Uptakeexocytosis, accumulation in nuclei, nuclear responses and DNA cleavage 06 Biological Sciences 0601 Biochemistry and Cell Biology. Part Fibre Toxicol. 2018;15(1):45. doi:10.1186/s12989-018-0279-8

73. Xu M, Zhu J, Wang F, et al. Improved In Vitro and In Vivo Biocompatibility of Graphene Oxide through Surface Modification: Poly(Acrylic Acid)-Functionalization is Superior to PEGylation. ACS Nano. 2016;10(3):3267-3281. doi:10.1021/acsnano.6b00539

74. Xue D, Chen E, Zhong H, et al. Immunomodulatory properties of graphene oxide for osteogenesis and angiogenesis. Int $J$ Nanomedicine. 2018;13:5799-5810. doi:10.2147/IJN.S170305

75. Yan J, Chen L, Huang CC, et al. Consecutive evaluation of graphene oxide and reduced graphene oxide nanoplatelets immunotoxicity on monocytes. Colloids Surfaces B Biointerfaces. 2017;153:300-309. doi:10.1016/j.colsurfb.2017.02.036

76. Xie Y, Wan B, Yang Y, Cui X, Xin Y, Guo LH. Cytotoxicity and autophagy induction by graphene quantum dots with different functional groups. J Environ Sci (China). 2019;77:198-209. doi:10.1016/j.jes.2018.07.014 
77. Yoon OJ, Kim I, Sohn IY, Kieu TT, Lee NE. Toxicity of graphene nanoflakes evaluated by cell-based electrochemical impedance biosensing. J Biomed Mater Res - Part A. 2014;102(7):2288-2294. doi:10.1002/jbm.a.34886

78. Yuan J, Gao H, Sui J, Duan H, Chen WN, Ching CB. Cytotoxicity evaluation of oxidized single-walled carbon nanotubes and graphene oxide on human hepatoma HepG2 cells: An iTRAQ-coupled 2D LC-MS/MS proteome analysis. Toxicol Sci. 2012;126(1):149-161. doi:10.1093/toxsci/kfr332

79. Yue H, Wei W, Yue Z, et al. The role of the lateral dimension of graphene oxide in the regulation of cellular responses. Biomaterials. 2012;33(16):4013-4021. doi:10.1016/j.biomaterials.2012.02.021

80. Zhang C, Feng X, He L, Zhang Y, Shao L. The interrupted effect of autophagic flux and lysosomal function induced by graphene oxide in p62-dependent apoptosis of F98 cells. $J$ Nanobiotechnology. 2020;18(1):52. doi:10.1186/s12951-020-00605-6

81. Zhang W, Yan L, Li M, et al. Deciphering the underlying mechanisms of oxidation-state dependent cytotoxicity of graphene oxide on mammalian cells. Toxicol Lett. 2015;237(2):61-71. doi:10.1016/j.toxlet.2015.05.021

82. Zhang X, Wei C, Li Y, et al. Dose-dependent cytotoxicity induced by pristine graphene oxide nanosheets for potential bone tissue regeneration. J Biomed Mater Res - Part A. 2020;108(3):614-624. doi:10.1002/jbm.a.36841

83. Zhang Y, Ali SF, Dervishi E, et al. Cytotoxicity effects of graphene and single-wall carbon nanotubes in neural phaeochromocytoma-derived pc12 cells. ACS Nano. 2010;4(6):31813186. doi:10.1021/nn1007176

84. Zhou $\mathrm{H}, \mathrm{Zhao} \mathrm{K,} \mathrm{Li} \mathrm{W,} \mathrm{et} \mathrm{al.} \mathrm{The} \mathrm{interactions} \mathrm{between} \mathrm{pristine} \mathrm{graphene} \mathrm{and} \mathrm{macrophages}$ and the production of cytokines/chemokines via TLR- and NF-KB-related signaling pathways. Biomaterials. 2012;33(29):6933-6942. doi:10.1016/j.biomaterials.2012.06.064

85. GY, C. et al. Simultaneous induction of autophagy and toll-like receptor signaling pathways by graphene oxide. Biomaterials 33, 6559-6569 (2012).

86. N, L., D, N., H, Y., W, W. \& G, M. Surface-engineered graphene navigate divergent biological outcomes toward macrophages. ACS Appl. Mater. Interfaces 7, 5239-5247 (2015).

87. Contreras-Torres, F. F. et al. Differential cytotoxicity and internalization of graphene family nanomaterials in myocardial cells. Mater. Sci. Eng. C 73, 633-642 (2017).

88. NGUYEN, T. H. D., LIN, M. \& MUSTAPHA, A. Toxicity of Graphene Oxide on Intestinal Bacteria and Caco-2 Cells. J. Food Prot. 78, 996-1002 (2015).

89. Mukherjee, S. P. et al. Next-Generation Sequencing Reveals Differential Responses to Acute versus Long-Term Exposures to Graphene Oxide in Human Lung Cells. Small 16, 1907686 (2020). 
90. Fusco, L. et al. Lateral dimension and amino-functionalization on the balance to assess the single-cell toxicity of graphene on fifteen immune cell types. NanoImpact 23, 100330 (2021).

91. Y, L. et al. Comparative proteomic analysis reveals cytotoxicity induced by graphene oxide exposure in A549 cells. J. Appl. Toxicol. 41, 1103-1114 (2021).

92. Li, J. et al. Lateral size of graphene oxide determines differential cellular uptake and cell death pathways in Kupffer cells, LSECs, and hepatocytes. Nano Today 37, 101061 (2021).

93. Lin, H. et al. Comparative Effects of Graphene and Molybdenum Disulfide on Human Macrophage Toxicity. Small 16, 2002194 (2020). 